\title{
Time-inconsistent preferences in a general equilibrium model
}

Citation for published version (APA):

Herings, P. J. J., \& Rohde, K. I. M. (2004). Time-inconsistent preferences in a general equilibrium model. METEOR, Maastricht University School of Business and Economics. METEOR Research Memorandum No. 017 https://doi.org/10.26481/umamet.2004017

Document status and date:

Published: 01/01/2004

DOI:

10.26481/umamet.2004017

Document Version:

Publisher's PDF, also known as Version of record

\section{Please check the document version of this publication:}

- A submitted manuscript is the version of the article upon submission and before peer-review. There can be important differences between the submitted version and the official published version of record.

People interested in the research are advised to contact the author for the final version of the publication, or visit the DOI to the publisher's website.

- The final author version and the galley proof are versions of the publication after peer review.

- The final published version features the final layout of the paper including the volume, issue and page numbers.

Link to publication

\footnotetext{
General rights rights.

- You may freely distribute the URL identifying the publication in the public portal. please follow below link for the End User Agreement:

www.umlib.nl/taverne-license

Take down policy

If you believe that this document breaches copyright please contact us at:

repository@maastrichtuniversity.nl

providing details and we will investigate your claim.
}

Copyright and moral rights for the publications made accessible in the public portal are retained by the authors and/or other copyright owners and it is a condition of accessing publications that users recognise and abide by the legal requirements associated with these

- Users may download and print one copy of any publication from the public portal for the purpose of private study or research.

- You may not further distribute the material or use it for any profit-making activity or commercial gain

If the publication is distributed under the terms of Article $25 \mathrm{fa}$ of the Dutch Copyright Act, indicated by the "Taverne" license above, 


\title{
Time-inconsistent Preferences in a General Equilibrium Model $^{1}$
}

\author{
P. Jean-Jacques Herings ${ }^{2} \quad$ Kirsten I.M. Rohde ${ }^{3}$
}

April 20, 2004

${ }^{1}$ The authors would like to thank Peter Wakker for helpful comments and suggestions.

${ }^{2}$ Department of Economics, Universiteit Maastricht, P.O. Box 616, 6200 MD Maastricht, The Netherlands. E-mail: P.Herings@algec.unimaas.nl. The author would like to thank the Netherlands Organisation for Scientific Research (NWO) for financial support.

${ }^{3}$ Department of Economics, Universiteit Maastricht, P.O. Box 616, 6200 MD Maastricht, The Netherlands. E-mail: K.Rohde@algec .unimaas.nl 


\begin{abstract}
This paper introduces time-inconsistent preferences in a multi-commodity general equilibrium framework with incomplete markets. The standard concept of competitive equilibrium is extended in order to allow for changes in intertemporal preferences. Depending on whether or not agents recognize that their intertemporal preferences change, agents are called sophisticated or naïve. This paper presents competitive equilibrium notions for economies with naïve agents and economies with sophisticated agents and provides assumptions under which both types of equilibria exist. Surprisingly, the set of naïve equilibria of societies populated by time-consistent households is not allocationally equivalent to the set of competitive equilibria. For sophisticated equilibria, the equivalence holds.

Time-inconsistency also raises conceptual issues about the appropriate concept of efficiency. Choices have to be made concerning the incorporation of future preferences and the appropriate instruments to create Pareto improvements. For both naive and sophisticated societies, we present four possible efficiency concepts. Suitable conditions are specified for which both naïve and sophisticated equilibria satisfy appropriate efficiency concepts.
\end{abstract}

Keywords: Time-inconsistent preferences, Competitive equilibrium, Equilibrium existence, Constrained efficiency

JEL classification: D51, D61, D91 


\section{Introduction}

The vast majority of the economic literature assumes that preferences are time-consistent. With time-consistent preferences a decision concerning a future date can be made at any period before that date and will not have to be reconsidered. Psychological research, however, has suggested that observed behavior is often time-inconsistent. Households frequently have intertemporal preferences that change over time. An example is a phenomenon known as hyperbolic discounting. There is an extensive body of literature that claims that people tend to be more patient in the long run than in the short run. While a person may prefer one apple today to two apples tomorrow at any point in time, he might prefer two apples eleven days from the current period to one apple ten days from that period. Hyperbolic discounting can explain this phenomenon while maintaining the assumption of constant instantaneous preferences, but exponential discounting cannot. For evidence of time-inconsistent behavior, we refer to Thaler (1991), Ainslie and Haslam (1992), Loewenstein and Prelec (1992), Rachlin and Raineri (1992), and Frederick, Loewenstein and O’Donoghue (2002).

This paper introduces time-inconsistent preferences in a multi-commodity general equilibrium framework with incomplete markets. We take a general perspective on timeinconsistent preferences, which incorporates hyperbolic and quasi-hyperbolic discounting as special cases. We model households as consisting of a different self in every period. Thus, no intrapersonal conflicts can arise when only one period is studied. This perspective differs from the one in Benhabib and Bisin (2002), who assume that at every period a household has two conflicting preferences.

We distinguish two types of societies, naïve and sophisticated ones. Naïve societies are populated by naïve households. These households do not realize that their intertemporal preferences change over time. Sophisticated societies consist of sophisticated households. A sophisticated household does realize that his intertemporal preferences will change in the future, and makes decisions today in order to anticipate these changes. We introduce the notions of naïve and sophisticated equilibrium as an extension of the usual notion of competitive equilibrium as applying to the time-consistent case. Surprisingly, the set of naïve equilibria of societies populated by time-consistent households is not allocationally equivalent to the set of competitive equilibria. For sophisticated equilibria, the equivalence holds. We give appropriate conditions under which both types of equilibria exist.

When intertemporal preferences change over time, the very definition of efficiency has to be reconsidered. Choices have to be made concerning the incorporation of future preferences and the appropriate instruments to create Pareto improvements. When efficiency is modeled as a program carried out by a social planner with certain objectives and instruments, we make a distinction between myopic and forward-looking social planners. We also 
distinguish planners who can change both actual and planned consumption and planners who can only change the former. For both naïve and sophisticated societies, this results in four possible efficiency concepts.

Related work on time-inconsistency in a general equilibrium setting has been done by Luttmer and Mariotti (2002, 2003), who study an infinite-horizon one-good model of an economy subject to uncertainty. Another related paper is the one of Krussel, Kuruşçu, and Smith (2002), who study an infinite horizon one-good model of a representative-agent economy without uncertainty. We will show how the efficiency concepts presented in those papers relate to our more general set-up.

The outline of this paper is as follows. Section 2 introduces the model. The definition and existence of competitive equilibria in naïve societies is the subject of Section 3. The definition of equilibrium and the proof of its existence for sophisticated economies is analyzed in Section 4. Sections 5 and 6 introduce the appropriate concepts of constrained optimality, and discuss them in relation to naïve and sophisticated economies. Section 5 considers myopic social planners, while Section 6 considers forward-looking social planners. Finally, Section 7 concludes. Proofs are in the Appendix.

\section{The Model}

Vector inequalities will be denoted by $\gg,>, \geq, \leq,<$, and $\ll$. We study a multi-period multi-commodity general equilibrium model with incomplete markets that is not subject to uncertainty. There are $T$ periods that are indexed by $t \in T$. In each period, the exchange economy consists of $H$ households, indexed by $h \in H$, and $L$ commodities, indexed by $l \in L{ }^{1}$

With respect to periods, a distinction should be made between a planning period and a consumption period. At planning period $t$, plans are made for consumption in periods $\tau \geq t$.

At planning period 1, households expect to have a consumption set $X_{\cdot \mid 1}^{h} \subset \mathbb{R}^{L T}$ for the remaining $T$ periods. It is assumed that households have correct expectations about their future consumption sets. This assumption implies that the consumption set at a planning period $t$ follows from the consumption plan realized so far and the consumption set $X_{. \mid 1}^{h}$. Throughout the paper, we assume that the consumption sets are independent of past consumption. ${ }^{2}$ Moreover, we will assume that $X_{\cdot \mid 1}^{h}=\mathbb{R}_{+}^{L T}$.

\footnotetext{
${ }^{1}$ Notice that $T$ indicates both the number of time periods, and the set of time periods. Similarly, $H$ $(L)$ indicates both the number of households (commodities) and the set of households (commodities). The context in which the symbol is used will make sure that no confusion can arise.

${ }^{2}$ Making the consumption sets depend on past consumption complicates the proofs of existence of equilibria. For instance, even when the endowments are in the interior of $X_{\cdot \mid 1}^{h}$, for certain realized consumption
} 
At every planning period $t$, households foresee an initial endowment $e_{\tau \mid t}^{h} \in \mathbb{R}^{L}$ for period $\tau$. Here again, households are assumed to have correct expectations, so $e_{\tau \mid t}^{h}$ is independent of the planning period $t$. At planning period $t$, the vector of all expected future endowments for household $h$ is represented by $e_{\cdot \mid t}^{h}=\left(e_{t \mid t}^{h}, \ldots, e_{T \mid t}^{h}\right)$.

At every planning period $t$, every household $h$ makes a consumption plan, which indicates how much it plans to consume in the current and future periods. For household $h$ the consumption in period $\tau$, as anticipated or planned in period $t$, is denoted by $x_{\tau \mid t}^{h} \in \mathbb{R}^{L}$. The planned consumption path for household $h$ at period $t$ is denoted by $x_{\cdot t}^{h}=\left(x_{t \mid t}^{h}, \ldots, x_{T \mid t}^{h}\right)$. For practical purposes some other notation will be used: $x_{-\mid t}^{h}=\left(x_{1 \mid 1}^{h}, \ldots, x_{t-1 \mid t-1}^{h}\right)$ equals actual consumption up to period $t, x_{\tau, \tau^{\prime} \mid t}^{h}=\left(x_{\tau \mid t}^{h}, \ldots, x_{\tau^{\prime} \mid t}^{h}\right)$ is consumption planned at period $t$ for the periods $\tau$ up to $\tau^{\prime}$, and $x^{h}=\left(x_{\cdot \mid 1}^{h}, \ldots, x_{\cdot \mid T}^{h}\right)$ denotes a consumption bundle, i.e. $T$ consumption paths, of household $h$. When we drop the superscript $h$, the $H$-tuple over all households is taken, for instance $x_{\mid t}=\left(x_{\cdot \mid t}^{1}, \ldots, x_{\cdot \mid t}^{H}\right)$. Similarly, if we drop the subscript $t$, the $T$-tuple over all time periods is considered, $x=\left(x_{\mid 1}, \ldots, x_{\cdot \mid T}\right)$. For all the preceding vectors, a subscript $l$ is added if attention is restricted to a particular commodity $l$. We define the set $X_{-\mid t}^{h}=\mathbb{R}_{+}^{L(t-1)}$. The sets $X_{\tau \mid t}^{h}, X_{\cdot \mid t}^{h}, X_{\tau, \tau^{\prime} \mid t}^{h}, X^{h}, X_{\tau \mid t}, X_{\cdot \mid t}$, and $X$ are defined by taking the appropriate projections and Cartesian products. In particular, we define $X_{\tau \mid t}^{h}=\mathbb{R}_{+}^{L}, X_{\cdot \mid t}^{h}=\mathbb{R}_{+}^{L(T-t+1)}, X_{\tau, \tau^{\prime} \mid t}^{h}=\mathbb{R}_{+}^{L\left(\tau^{\prime}-\tau+1\right)}, X^{h}=\mathbb{R}_{+}^{L T(T+1) / 2}, X_{\cdot \mid t}=\prod_{h \in H} X_{\cdot \mid t}^{h}$, and $X=\prod_{h \in H^{\prime}} X^{h}$.

We call $x \in X$ an allocation. Notice that $x$ consists of $T$ consumption paths for the entire economy, each one starting at a different time period. Consumption paths starting at different time periods are not necessarily consistent. We explicitly allow for the possibility that $x_{\tau \mid t} \neq x_{\tau \mid t^{\prime}}$. An allocation is called time-consistent if at all periods the same consumption is planned for a given future period. This is formally expressed by the following definition.

\section{Definition 2.1 Time-consistent Allocation}

An allocation $x$ is time-consistent if, for every $h \in H$, for every $t \in T$ we have $x_{\cdot \mid t}^{h}=x_{t, T \mid 1}^{h}$.

At every planning period, every household has preferences over present and future consumption bundles. These preferences may depend on consumption in the past. Preferences of household $h$ at planning period $t$, given past consumption $x_{-\mid t}^{h}$, are represented by the preference relation $\succeq_{x_{-\mid t}^{h}}^{h, t}$ defined on $X_{\cdot \mid t}^{h} \times X_{\cdot \mid t}^{h}$. With slight abuse of notation we will often write $\succeq_{x_{-\mid t}^{h}}$ instead of $\succeq_{x_{-\mid t}^{h, t}}^{h,}$. When past consumption is clear from the context, it is sometimes omitted from the notation, and the preferences of household $h$ at planning period $t$ are denoted by $\succeq^{h, t}$. The preference $\succeq^{h}$ of household $h$ is the collection of preferences

plans they might be on the boundary of the consumption set at a future planning period. 
at all possible planning periods, contingent on all possible historical consumption paths, $\succeq^{h}=\left(\succeq_{x_{-\mid t}^{h}}\right)_{t \in T, x_{-\mid t}^{h} \in X_{-\mid t}^{h}}$.

An economy is described by its primitives, being consumption sets, preferences, and endowments: $\mathcal{E}=\left(X^{h}, \succeq^{h}, e^{h}\right)_{h \in H}$.

Consider two consumption paths that coincide up to period $t^{\prime}>t$. Preferences of a household are said to be time-consistent if the household prefers one consumption path over the other at period $t^{\prime}$ if and only if it does so at period $t$.

\section{Definition 2.2 Time-consistent Preferences}

Preferences for household $h$ are time-consistent if for all periods $t, t^{\prime} \in T$ with $t<t^{\prime}$, for every $x_{-\mid t}^{h} \in X_{-\mid t}^{h}$, and $x_{\cdot \mid t}^{h}, \bar{x}_{\cdot \mid t}^{h} \in X_{\cdot \mid t}^{h}$ with $x_{t, t^{\prime}-1 \mid t}^{h}=\bar{x}_{t, t^{\prime}-1 \mid t}^{h}$ we have

$$
x_{\cdot \mid t}^{h} \succeq_{x_{-\mid t}^{h}}^{h, t} \bar{x}_{\cdot \mid t}^{h} \text { if and only if } x_{t^{\prime}, T \mid t}^{h} \succeq_{\left(x_{-\mid t}^{h}, x_{t, t^{\prime}-1 \mid t}^{h}\right)}^{h, t^{\prime}} \bar{x}_{t^{\prime}, T \mid t}^{h}
$$

Preferences are said to be time-inconsistent if they are not time-consistent. ${ }^{3}$

The following lemma shows that for the verification of time-consistency of preferences it suffices to make only comparisons involving period 1 and period $t$. The proofs of all lemmas and theorems are in the appendix.

\section{Lemma 2.3}

If the preferences of household $h$ are such that for every $t \in T$, for every $x_{\cdot \mid 1}^{h}, \bar{x}_{\cdot \mid 1}^{h} \in X_{\cdot \mid 1}^{h}$ with $x_{1, t-1 \mid 1}^{h}=\bar{x}_{1, t-1 \mid 1}^{h}$,

$$
x_{\cdot \mid 1}^{h} \succeq^{h, 1} \bar{x}_{\cdot \mid 1}^{h} \text { if and only if } x_{t, T \mid 1}^{h} \succeq_{x_{1, t-1 \mid 1}^{h, t}}^{h,} \bar{x}_{t, T \mid 1}^{h},
$$

then the preferences of household $h$ are time-consistent.

One of the implications of the lemma is that knowledge of the preference relation $\succeq^{h, 1}$, together with the requirement of time-consistency, is sufficient for the derivation of all preference relations $\succeq^{h, t}$.

The consumption paths chosen by the households depend on current and expected future prices. In period $t$, the expected prices for period $\tau$ are denoted by $p_{\tau \mid t} \in P_{\tau \mid t}=\mathbb{R}^{L}$. As before, the vector of expected prices, at planning period $t$, for present and future periods is denoted by $p_{\cdot \mid t}=\left(p_{t \mid t}, \ldots, p_{T \mid t}\right)$. The set of admissible price systems $P_{. \mid t}$ is defined accordingly. The expected prices, at planning period $t$, for periods $\tau$ up to $\tau^{\prime}$ are denoted by $p_{\tau, \tau^{\prime} \mid t}=\left(p_{\tau \mid t}, \ldots, p_{\tau^{\prime} \mid t}\right)$, and the complete price system over all periods is

\footnotetext{
${ }^{3}$ Note that we allow for a more general set of preferences than Laibson (1997, 1998), Angeletos et al. (2001) and Luttmer and Mariotti (2002, 2003), since we allow for preferences that are not timeseparable.
} 
represented by $p=\left(p_{\cdot \mid 1}, \ldots, p_{\cdot \mid T}\right)$, where $P$ is defined appropriately. Finally, realized prices up to period $t$ are represented by $p_{-\mid t}=\left(p_{1 \mid 1}, \ldots, p_{t-1 \mid t-1}\right)$.

We follow Pollak (1968), in distinguishing between naïve and sophisticated households. Naïve households are not aware of their changing preferences. They do not realize that in the future they might be willing to reconsider choices made today. Thus, when making a consumption decision in planning period $t$, a naïve household $h$ only takes into account the prevailing preferences at that particular period, $\succeq_{x_{-\mid t}^{h}}$. Sophisticated households, on the other hand, are aware of their changing preferences and will take them into account when making current decisions. They will only consider future plans that they expect to stick to. That is, when planning future consumption in period $t$, they incorporate $\succeq_{x_{-\mid \tau}^{h}}$ for all $\tau \geq t$.

First, the behavior of naïve households is addressed. Demand and supply of commodities is identified and the existence of an equilibrium is established. An example illustrates the intuition behind the model. The following assumptions will be made throughout the paper:

Ass. 1 For every $h \in H$, for every $t \in T$, the consumption set $X_{\cdot \mid t}^{h}=\mathbb{R}_{+}^{L(T-t+1)}$.

Ass. 2 For every $h \in H, t \in T$, and $x_{-\mid t}^{h} \in X_{-\mid t}^{h}$, the preference relation $\succeq_{-x_{-\mid t}^{h}}$ is complete, transitive, and continuous on $X_{\cdot \mid t}^{h} \times X_{\cdot \mid t}^{h}$.

Ass. 3 For every $h \in H, t \in T$, and $x_{-\mid t}^{h} \in X_{-\mid t}^{h}$, the preference relation $\succeq_{x_{-\mid t}^{h}}$ is monotone, i.e. for $x_{\cdot \mid t}^{h}, \bar{x}_{\cdot \mid t}^{h} \in X_{\cdot \mid t}^{h}$ with $\bar{x}_{\cdot \mid t}^{h} \geq x_{\cdot \mid t}^{h}$ and $\bar{x}_{\tau \mid t}^{h} \gg x_{\tau \mid t}^{h}$ for some $\tau \geq t$, we have $\bar{x}_{\cdot \mid t}^{h} \succ_{x_{-\mid t}^{h}} x_{\cdot \mid t}^{h}$.

Ass. 4 For every $h \in H, t \in T$, and $x_{-\mid t}^{h} \in X_{-\mid t}^{h}$, the preference relation $\succeq_{x_{-\mid t}^{h}}$ is convex in present and future consumption, i.e. for $x_{\cdot \mid t}^{h}, \bar{x}_{\cdot \mid t}^{h} \in X_{\cdot \mid t}^{h}$ with $\bar{x}_{\cdot \mid t}^{h} \succ_{x_{-\mid t}^{h}} x_{\cdot \mid t}^{h}$ we have $\alpha \bar{x}_{\cdot \mid t}^{h}+(1-\alpha) x_{\cdot \mid t}^{h} \succ_{x_{-\mid t}^{h}} x_{\cdot \mid t}^{h}$ for any $\alpha \in(0,1)$.

Ass. 5 For every $h \in H, e_{\cdot \mid 1}^{h} \gg 0$.

A preference relation $\succeq$ is continuous on $X \times X$ if for all $x \in X$ we have that $\{y \in$ $X: y \succeq x\}$ and $\{y \in X: y \preceq x\}$ are closed in $X$. The completeness, transitivity and continuity assumptions on preferences ensure that there are continuous utility functions $u_{x_{-\mid t}^{h}}$ representing the preferences.

\section{Naïve Societies}

This section considers naïve households. We treat the most simple incomplete markets case, where links between periods result from intertemporal preferences only. In planning 
period $t$, given a price vector $p_{\text {.|t }}$, the naïve household will have to make sure that in each future period the value of its consumption bundle in that period does not exceed the value of its endowment. That is, the opportunity set of the naïve household $h$ at period $t$ is defined by

$$
\gamma_{t}^{h}\left(p_{\cdot \mid t}\right)=\left\{x_{\cdot \mid t}^{h} \in X_{\cdot \mid t}^{h} \mid p_{\tau \mid t} x_{\tau \mid t}^{h} \leq p_{\tau \mid t} e_{\tau \mid t}^{h} \text { for all } \tau \geq t\right\}
$$

The demand set of household $h$ at period $t$ is then given by

$$
\delta_{t}^{h}\left(p_{\cdot \mid t}, x_{-\mid t}^{h}\right)=\left\{\tilde{x}_{\cdot \mid t}^{h} \in \gamma_{t}^{h}\left(p_{\cdot \mid t}\right) \mid \tilde{x}_{\cdot \mid t}^{h} \succeq_{x_{-\mid t}^{h}} x_{\cdot \mid t}^{h} \text { for all } x_{\cdot \mid t}^{h} \in \gamma_{t}^{h}\left(p_{\cdot \mid t}\right)\right\} .
$$

In a standard competitive analysis, preferences are implicitly assumed to be time-consistent. In our more general setting, one could define a competitive equilibrium as follows.

\section{Definition 3.1 Competitive Equilibrium}

A pair $\left(p_{\cdot \mid 1}^{*}, x_{\cdot \mid 1}^{*}\right) \in P_{\cdot \mid 1} \times X_{\cdot \mid 1}$ is a competitive equilibrium of the economy $\mathcal{E}$ if

(a) for all households $h \in H, x_{\cdot \mid 1}^{* h} \in \delta_{1}^{h}\left(p_{\cdot \mid 1}^{*}\right)$,

(b) $\sum_{h \in H} x_{\cdot \mid 1}^{* h}=\sum_{h \in H} e_{\cdot \mid 1}^{h}$.

This definition only concerns the behavior in the first period. Obviously, this makes sense only if preferences are time-consistent. Another implicit assumption in the definition of competitive equilibrium in the standard setting is that allocations are time-consistent, as well as expectations of future prices. This observation leads to the following concept of extended competitive equilibrium.

\section{Definition 3.2 Extended Competitive Equilibrium}

A pair $\left(p^{*}, x^{*}\right) \in P \times X$ is an extended competitive equilibrium of the economy $\mathcal{E}$ if

(a) $\left(p_{\cdot \mid 1}^{*}, x_{\cdot \mid 1}^{*}\right)$ is a competitive equilibrium,

(b) $p_{\cdot \mid t}^{*}=p_{t, T \mid 1}^{*}$ for every $t \in T$, and

(c) $x_{\cdot \mid t}^{* h}=x_{t, T \mid 1}^{* h}$ for every $h \in H$ and every $t \in T$.

To define a competitive equilibrium that is appropriate for the study of economies with time-inconsistent preferences, we first assume that all households are naïve and maximize their utilities given past consumption. Thus, at any given price system, every household demands a future consumption path that is in its demand set. The price system and demanded consumption bundles will constitute an equilibrium if at any planning period, for every commodity, the total demand for that commodity does not exceed the total endowment of that commodity. Since preferences can be time-inconsistent, it may well be that the planned consumption bundles and prices will not be equal to the actual consumption bundles and prices. However, naïve households are not able to foresee their changing 
preferences and the resulting changing consumption bundles and prices. Thus, at an equilibrium price system there is no household that wants to deviate at any period from the consumption plan at that period, given the prices and price expectations at that period. This leads to the following definition of an equilibrium for naïve households.

\section{Definition 3.3 Naïve Equilibrium}

A pair $\left(p^{*}, x^{*}\right) \in P \times X$ is a naive equilibrium of the economy $\mathcal{E}$ if

(a) $x_{\cdot \mid t}^{* h} \in \delta_{t}^{h}\left(p_{\cdot \mid t}^{*}, x_{-\mid t}^{* h}\right)$ for all $h \in H$ and all $t \in T$,

(b) $\sum_{h \in H} x_{\mid t}^{* h}=\sum_{h \in H} e_{\mid t}^{h}$ for all $t \in T$.

The following theorem claims that the set of extended competitive equilibria is a subset of the set of naïve equilibria if preferences are time-consistent.

\section{Theorem 3.4}

If preferences of all households are time-consistent, then an extended competitive equilibrium of the economy $\mathcal{E}$ is a naïve equilibrium.

The following example shows that the converse is not necessarily true. A naïve equilibrium is constructed such that the expectations in the first period of the second period prices are not correct. Moreover, would the expected prices have been replaced by the realized prices in the second period, such that expectations would have been correct, then this would not have yielded an equilibrium in the first period. We even show that the allocation that arises if we replace expected consumption by actual consumption in the second period, is not compatible with any extended competitive equilibrium, even though all preferences are time-consistent.

\section{Example 3.5}

Consider an economy with two naïve households, two goods and two periods. The endowments of the households are $e_{|| 1}^{1}=\left(e_{1 \mid 1}^{1}, e_{2 \mid 1}^{1}\right)=(1,2,0,4)$ and $e_{|| 1}^{2}=\left(e_{1 \mid 1}^{2}, e_{2 \mid 1}^{2}\right)=(2,1,4,0)$. The time-consistent preferences are given by

$$
u^{1}\left(x_{1 \mid 1}^{1}, x_{2 \mid 1}^{1}\right)=\left\{\begin{array}{r}
\min \left(x_{1,1 \mid 1}^{1}, x_{1,2 \mid 1}^{1}, x_{2,1 \mid 1}^{1}, x_{2,2 \mid 1}^{1}\right) \\
\text { if } \min \left(x_{1,1 \mid 1}^{1}, x_{1,2 \mid 1}^{1}, x_{2,1 \mid 1}^{1}, x_{2,2 \mid 1}^{1}\right) \leq 1 \\
{\left[\left(x_{1,1 \mid 1}^{1}-1\right)\left(x_{1,2 \mid 1}^{1}-1\right)\left(x_{2,1 \mid 1}^{1}-1\right)\left(x_{2,2 \mid 1}^{1}-1\right)\right]^{1 / 4}+1} \\
\text { if } \min \left(x_{1,1 \mid 1}^{1}, x_{1,2 \mid 1}^{1}, x_{2,1 \mid 1}^{1}, x_{2,2 \mid 1}^{1}\right) \geq 1
\end{array}\right.
$$

for household 1 and

$$
u^{2}\left(x_{1 \mid 1}^{2}, x_{2 \mid 1}^{2}\right)=\min \left(x_{1,1 \mid 1}^{2}, x_{1,2 \mid 1}^{2}, x_{2,1 \mid 1}^{2}, x_{2,2 \mid 1}^{2}\right)
$$


for household 2 .

Consider prices $p^{*}$ such that $p_{\cdot \mid 1}^{*}=(1,2,4,1)$ and $p_{\cdot \mid 2}^{*}=(3,4)$. Then for household 1 we have $\min \left(x_{2,1 \mid 1}^{1}, x_{2,2 \mid 1}^{1}\right) \leq 4 / 5<1$. Thus, $x_{\cdot \mid 1}^{* 1}=\left(1 \frac{2}{3}, 1 \frac{2}{3}, \frac{4}{5}, \frac{4}{5}\right)$ is an optimal consumption bundle for household 1. Moreover, $x_{\cdot \mid 1}^{* 2}=\left(1 \frac{1}{3}, 1 \frac{1}{3}, \frac{16}{5}, \frac{16}{5}\right)$ is an optimal consumption bundle for household 2. By time-consistency of preferences, when arriving in the second period, the households maximize the following utility functions

$$
u^{1}\left(x_{1 \mid 1}^{* 1}, x_{2 \mid 2}^{1}\right)= \begin{cases}\min \left(1 \frac{2}{3}, 1 \frac{2}{3}, x_{2,1 \mid 2}^{1}, x_{2,2 \mid 2}^{1}\right) & \text { if } \min \left(x_{2,1 \mid 2}^{1}, x_{2,2 \mid 2}^{1}\right) \leq 1 \\ {\left[\frac{2}{3} \cdot \frac{2}{3} \cdot\left(x_{2,1 \mid 2}^{1}-1\right)\left(x_{2,2 \mid 2}^{1}-1\right)\right]^{1 / 4}+1} & \text { if } \min \left(x_{2,1 \mid 2}^{1}, x_{2,2 \mid 2}^{1}\right) \geq 1\end{cases}
$$

and

$$
u^{2}\left(x_{1 \mid 1}^{* 2}, x_{2 \mid 2}^{2}\right)=\min \left(1 \frac{1}{3}, 1 \frac{1}{3}, x_{2,1 \mid 2}^{2}, x_{2,2 \mid 2}^{2}\right)
$$

With prices $p_{\cdot \mid 2}^{*}$, the second-period budget constraint for household 1 implies that $x_{2,2 \mid 2}^{1}=$ $4-3 x_{2,1 \mid 2}^{1} / 4$. The first household then maximizes $\left(x_{2,1 \mid 2}^{1}-1\right)\left(x_{2,2 \mid 2}^{1}-1\right)$ subject to that budget constraint, which yields $x_{2 \mid 2}^{* 1}=\left(2 \frac{1}{2}, 2 \frac{1}{8}\right)$. For household $2, x_{2 \mid 2}^{* 2}=\left(1 \frac{1}{2}, 1 \frac{7}{8}\right)$ is an optimal consumption bundle. Thus, $\left(p^{*}, x^{*}\right)$ is a naïve equilibrium.

The allocation $\left(\left(x_{1 \mid 1}^{* 1}, x_{2 \mid 2}^{* 1}\right),\left(x_{1 \mid 1}^{* 2}, x_{2 \mid 2}^{* 2}\right)\right)=\left(\left(1 \frac{2}{3}, 1 \frac{2}{3}, 2 \frac{1}{2}, 2 \frac{1}{8}\right),\left(1 \frac{1}{3}, 1 \frac{1}{3}, 1 \frac{1}{2}, 1 \frac{7}{8}\right)\right)$ cannot be a competitive equilibrium allocation. Suppose to the contrary that this allocation is a competitive equilibrium allocation. Since household 1 demands more than one unit of each good for the second period, it maximizes $\left(x_{1,1 \mid 1}^{1}-1\right)\left(x_{1,2 \mid 1}^{1}-1\right)$ in the first period subject to the budget constraint. By deriving the first-order conditions of that problem, it can easily be seen that household 1 will demand an equal amount of both goods in the first period only if $p_{1,1 \mid 1}=p_{1,2 \mid 1}$. But then again, it would demand $1 \frac{1}{2}$ units of each good in the first period, instead of $1 \frac{2}{3}$ units. Thus, we arrive at a contradiction. This shows that $\left(\left(x_{1 \mid 1}^{* 1}, x_{2 \mid 2}^{* 1}\right),\left(x_{1 \mid 1}^{* 2}, x_{2 \mid 2}^{* 2}\right)\right)$ cannot be a competitive equilibrium allocation. By similar arguments, $p=(1,2,3,4)$ cannot be a competitive equilibrium price system.

Although a naïve equilibrium allocation might be incompatible with any extended competitive equilibrium, a weaker result can be obtained. If preferences are time-consistent and a naïve equilibrium exists, then at least one of the naïve equilibria is an extended competitive equilibrium as well. This is shown in the next theorem.

\section{Theorem 3.6}

Assume that preferences are time-consistent. If a naïve equilibrium exists in the economy $\mathcal{E}$, then also an extended competitive equilibrium exists. 
A naïve equilibrium can be shown to exist under standard assumptions.

\section{Theorem 3.7 (Existence of naïve equilibrium)}

If the economy $\mathcal{E}$ satisfies Assumptions $1-5$, then there exists a naïve equilibrium $\left(p^{*}, x^{*}\right)$.

The proof of the theorem requires an induction argument. That is, we first establish the existence of equilibrium prices and allocations as planned in the first period. Then given the first period equilibrium, we show the existence of equilibrium prices and allocations as planned in the second period, and so on.

\section{Sophisticated Societies}

This section considers sophisticated households. Again, we treat the most simple incomplete markets case, where links between periods result from intertemporal preferences only. The introduction of sophisticated households gives rise to new phenomena. The difference between a naïve and a sophisticated household is that the former is not aware of its changing preferences, whereas the latter is. A sophisticated household will only make consumption plans for the future that it expects to actually stick to. A sophisticated household can be seen as consisting of different selves, where the first self acts first and the next selves act subsequently. The behavior of the household can then be modeled as a game where the players are the different selves. A sophisticated household will only play a subgame-perfect Nash equilibrium of that game.

In the last period, no plans for the future are made. Thus, in the last period, the opportunity and demand sets of the sophisticated households resemble those for the naïve households. More specifically, the opportunity set in the last period is defined by

$$
\phi_{T}^{h}\left(p_{\cdot \mid T}, x_{-\mid T}^{h}\right)=\left\{x_{\cdot \mid T}^{h} \in X_{\cdot \mid T}^{h} \quad \mid p_{T \mid T} x_{T \mid T}^{h} \leq p_{T \mid T} e_{T \mid T}^{h}\right\} .
$$

The set of optimal consumption bundles in the last period is given by

$$
\xi_{T}^{h}\left(p_{\cdot \mid T}, x_{-\mid T}^{h}\right)=\left\{\tilde{x}_{\cdot \mid T}^{h} \in \phi_{T}^{h}\left(p_{\cdot \mid T}, x_{-\mid T}^{h}\right) \mid \tilde{x}_{\cdot \mid T}^{h} \succeq_{x_{-\mid T}^{h}} x_{\cdot \mid T}^{h} \text { for all } x_{\cdot \mid T}^{h} \in \phi_{T}^{h}\left(p_{\cdot \mid T}, x_{-\mid T}^{h}\right)\right\} .
$$

The opportunity sets in earlier periods are similar to those for the naïve households, except for the fact that the sophisticated household restricts himself to future consumption plans that are in his future demand sets at the expected future prices. That is, the opportunity set for the sophisticated household $h$ in period $t, t<T$, is defined by

$$
\begin{aligned}
\phi_{t}^{h}\left(p_{\cdot \mid t}, x_{-\mid t}^{h}\right)=\left\{x_{\cdot \mid t}^{h} \in X_{\cdot \mid t}^{h} \mid \quad p_{\tau \mid t} x_{\tau \mid t}^{h}\right. & \leq p_{\tau \mid t} e_{\tau \mid t}^{h} \quad \text { for all } \tau \geq t, \text { and } \\
x_{t+1, T \mid t}^{h} & \left.\in \xi_{t+1}^{h}\left(p_{t+1, T \mid t}, x_{-\mid t}^{h}, x_{t \mid t}^{h}\right)\right\} .
\end{aligned}
$$


Since preferences depend on past consumption, the opportunity sets also depend on past consumption. The demand set for household $h$ in period $t, t<T$, is then given by:

$$
\xi_{t}^{h}\left(p_{\cdot \mid t}, x_{-\mid t}^{h}\right)=\left\{\tilde{x}_{\cdot \mid t}^{h} \in \phi_{t}^{h}\left(p_{\cdot \mid t}, x_{-\mid t}^{h}\right) \mid \tilde{x}_{\cdot \mid t}^{h} \succeq_{x_{-\mid t}^{h}} x_{\cdot \mid t}^{h} \text { for all } x_{\cdot \mid t}^{h} \in \phi_{t}^{h}\left(p_{\cdot \mid t}, x_{-\mid t}^{h}\right)\right\} .
$$

We introduce the following equilibrium concept for sophisticated societies.

\section{Definition 4.1 Sophisticated Equilibrium}

A pair $\left(p^{*}, x^{*}\right) \in P \times X$ is a sophisticated equilibrium if

(a) $x_{\cdot t}^{* h} \in \xi_{t}^{h}\left(p_{\cdot \mid t}^{*}, x_{-\mid t}^{* h}\right)$ for all $h \in H$ and all $t \in T$,

(b) $\sum_{h \in H} x_{\cdot \mid t}^{* h}=\sum_{h \in H} e_{\cdot \mid t}^{h}$ for all $t \in T$,

(c) $p_{t^{\prime}, T \mid t}^{*}=p_{\cdot \mid t^{\prime}}^{*}$ for all $t, t^{\prime} \in T$ with $t \leq t^{\prime}$,

(d) $x_{t^{\prime}, T \mid t}^{* h}=x_{\cdot t^{\prime}}^{* h}$ for all $t, t^{\prime} \in T$ with $t \leq t^{\prime}$.

As sophisticated households make plans that they will stick to in the future, we follow Arrow (1953) and Radner (1972) and define an equilibrium price system in such a way that expected prices are equal to actual prices, i.e. that households have correct point expectations about future prices. ${ }^{4}$ Furthermore, it is also assumed that consumption choices will not have to be reconsidered.

The next theorem presents a characterization of the notion of sophisticated equilibrium.

\section{Theorem 4.2}

$A$ pair $\left(p^{*}, x^{*}\right) \in P \times X$ is a sophisticated equilibrium if and only if it satisfies the following conditions:

(i) $x_{\cdot \mid 1}^{* h} \in \xi_{1}^{h}\left(p_{\cdot \mid 1}^{*}\right)$ for all $h \in H$,

(ii) $\sum_{h \in H} x_{\cdot \mid 1}^{* h}=\sum_{h \in H} e_{\cdot \mid 1}^{h}$ for all $h \in H$,

(iii) $p_{\cdot \mid t}^{*}=p_{t, T \mid 1}^{*}$ for all $t \in T$,

(iv) $x_{\cdot \mid t}^{* h}=x_{t, T \mid 1}^{* h}$ for all $h \in H$ and all $t \in T$.

The next result shows that if preferences are time-consistent, then the set of sophisticated equilibria coincides with the set of extended competitive equilibria.

\section{Theorem 4.3}

Assume that the preferences of all households are time-consistent and that Assumptions 12 hold. A pair $\left(p^{*}, x^{*}\right) \in P \times X$ with $p^{*} \gg 0$ is a sophisticated equilibrium of the economy $\mathcal{E}$ if and only if it is an extended competitive equilibrium.

\footnotetext{
${ }^{4}$ See Dutta and Morris (1997) for alternatives to the concept of rational expectations as used by Arrow (1953) and Radner (1972).
} 
We will establish the existence of a sophisticated equilibrium under some additional assumptions. Therefore, we first define independence of past consumption.

\section{Definition 4.4 Independence of past consumption}

Preferences are independent of past consumption when $\succeq_{x_{-\mid t}^{h}}=\succeq_{\bar{x}_{-\mid t}^{h}}$ for every $x_{-\mid t}^{h}, \bar{x}_{-\mid t}^{h} \in$ $X_{-\mid t}^{h}$.

The additional assumptions are as follows:

Ass. 4' For every $h \in H, t \in T$, and $x_{-\mid t}^{h} \in X_{-\mid t}^{h}$, the preference relation $\succeq_{x_{-\mid t}^{h}}$ is strictly convex in present and future consumption, i.e. for $x_{\cdot \mid t}^{h}, \bar{x}_{\cdot \mid t}^{h} \in X_{\cdot \mid t}^{h}$ with $\bar{x}_{\cdot \mid t}^{h} \succeq_{x_{-\mid t}^{h}} x_{\cdot \mid t}^{h}$ and $\bar{x}_{\cdot \mid t}^{h} \neq x_{\cdot \mid t}^{h}$ we have $\alpha \bar{x}_{\cdot \mid t}^{h}+(1-\alpha) x_{\cdot \mid t}^{h} \succ_{x_{-\mid t}^{h}} x_{\cdot \mid t}^{h}$ for any $\alpha \in(0,1)$.

Ass. 6 Preferences are independent of past consumption.

Assumption 6 does not allow for habit formation, where consumption depends on consumption in the past. However, it does allow for intertemporal utility functions that discount hyperbolically or quasi-hyperbolically conform Frederick, Loewenstein and O'Donoghue (2002).

\section{Theorem 4.5 Existence of sophisticated equilibrium}

If the economy $\mathcal{E}$ satisfies Assumptions 1-6 and 4', then there exists a sophisticated equilibrium $\left(p^{*}, x^{*}\right)$.

If Assumption 6 is not satisfied, it may well happen that an equilibrium does not exist. In that case, it cannot be guaranteed that demand correspondences are convex-valued. Then it is not difficult to construct examples where no equilibrium exists.

The existence proof is standard and can be found in the appendix. The major complication to be taken care of is the part of the proof that shows a sophisticated equilibrium of the compactified economy to remain an equilibrium after the bounds on consumption sets have been removed.

\section{$5 \quad$ Efficiency - the Myopic Case}

When intertemporal preferences change over time, the very definition of efficiency has to be reconsidered. Choices have to be made concerning the incorporation of future preferences in the efficiency notion used and the appropriate instruments allowed to create Pareto improvements. When efficiency is modeled as a program carried out by a social planner with certain objectives and instruments, we can we make a distinction between myopic and forward-looking social planners. Myopic social planners care only about the current 
self of every household. Forward-looking social planners take all selves of every household into account. As far as instruments are concerned, we distinguish between social planners who can modify both actual and planned consumption and social planners who can only change actual consumption. For the former type of social planner there exists a naïve and a sophisticated version, where the latter type sticks to time-consistent allocations. We will show that for the myopic case this distinction is immaterial.

\begin{tabular}{|c|c|c|c|c|}
\hline & \multicolumn{3}{|c|}{ Instruments } \\
\hline & & \multirow[t]{2}{*}{ Current Consumption } & \multicolumn{2}{|c|}{ Current and Planned Consumption } \\
\hline & & & Naïve Societies & Sophisticated Societies \\
\hline \multirow[t]{2}{*}{ Goals } & Myopic & $\begin{array}{c}\text { CMP } \\
\text { Section 5.2 }\end{array}$ & $\begin{array}{c}\text { MOP } \\
\text { Section } 5.1\end{array}$ & $\begin{array}{c}\text { MOP } \\
\text { Section } 5.1\end{array}$ \\
\hline & Forward-looking & $\begin{array}{c}\text { CP } \\
\text { Section 6.2 }\end{array}$ & $\begin{array}{c}\text { OP } \\
\text { Section } 6.1\end{array}$ & $\begin{array}{c}\text { TCOP } \\
\text { Section } 6.1\end{array}$ \\
\hline
\end{tabular}

Table 1: Summary of efficiency concepts.

This section considers social planners who care only about the current self of each household. When a social planner takes into account only the intertemporal preferences of the households in one particular period, this can mean that the social planner cares only about the selves corresponding to the period in which the planner is active and is myopic in that it forgets to realize that the preferences of future selves might differ from the ones of current selves. Another interpretation is that the social planner has reasons to believe that the preferences of the current selves of the households are the true underlying preferences of the households and that the preferences of the future selves of the households are distorted preferences.

\subsection{Myopic Overall Pareto Efficiency}

In this subsection we assume that social planners are myopic and can alter both actual and planned consumption. An allocation is called myopic overall Pareto efficient if there is no planning period $t$ where actual consumption in that particular period could be reallocated in such a way that every household would be at least as well off in that period as at the original allocation, whereas one household would be strictly better off than at the original allocation. 


\section{Definition 5.1 Myopic Overall Pareto (MOP) Efficiency}

The allocation $x^{*}$ is myopic overall Pareto (MOP) efficient if there is no allocation $\tilde{x}$ and no period $t^{\prime}$ such that

(i) $\sum_{h \in H} \tilde{x}_{\cdot \mid t^{\prime}}^{h}=\sum_{h \in H} e_{\cdot \mid t^{\prime}}^{h}$,

(ii) $\tilde{x}_{\cdot \mid t^{\prime}}^{h} \succeq_{x_{-\mid t^{\prime}}^{* h}} x_{\mid t^{\prime}}^{* h}$ for all $h \in H$, and

(iii) $\tilde{x}_{\cdot t^{\prime}}^{h^{\prime}} \succ_{x_{-\mid t^{\prime}}^{*}} x_{\cdot \mid t^{\prime}}^{* h^{\prime}}$ for some $h^{\prime} \in H$.

The intuition behind this definition is as follows. In every planning period $t$ there is a social planner who seeks to maximize only the preferences of the selves of the households at period $t$. The social planner reallocates both current and planned consumption. Now an equilibrium is called MOP efficient if there is no sequence of social planners that behave as described and that can make at least one household better off than in equilibrium, while not making any household worse off. If preferences do not depend on past consumption this concept corresponds to "date-t Pareto efficiency" for every $t$ as introduced in Luttmer and Mariotti (2002). In addition, a MOP efficient allocation is renegotiation-proof in the sense of Luttmer and Mariotti (2002).

MOP efficiency is closely related to unconstrained Pareto efficiency. In our multiperiod context, by restricting attention to the preferences of households at period 1, Pareto efficiency could be defined as follows.

\section{Definition 5.2 Pareto Efficiency}

The allocation $x^{*}$ is Pareto efficient if there is no allocation $\tilde{x}$ such that

(i) $\sum_{h \in H} \tilde{x}_{\cdot \mid 1}^{h}=\sum_{h \in H} e_{\cdot \mid 1}^{h}$,

(ii) $\tilde{x}_{\cdot \mid 1}^{h} \succeq^{h, 1} x_{\cdot \mid 1}^{* h}$ for all $h \in H$, and

(iii) $\tilde{x}_{\mid 11}^{h^{\prime}} \succ^{h^{\prime}, 1} x_{\cdot \mid 1}^{* h^{\prime}}$ for some $h^{\prime} \in H$.

The following theorem shows that the two concepts are equivalent when preferences are time-consistent and when attention is restricted to time-consistent allocations.

\section{Theorem 5.3}

Assume that preferences are time-consistent. Then a time-consistent allocation is MOP efficient if and only if it is Pareto efficient.

In settings with incomplete markets, it has been shown that equilibria are typically not Pareto efficient. Generically, they are not even efficient when weaker efficiency concepts are 
used. ${ }^{5}$ Therefore, since we have a sequence of markets that do not allow for intertemporal income transfers, examples that show that naïve and sophisticated equilibria may be MOP inefficient can easily be found.

\subsection{Constrained Myopic Periodical Efficiency}

In this subsection we assume that a social planner can only reallocate commodities in the current period. This leads to the following definition.

\section{Definition 5.4 Constrained Myopic Periodical (CMP) Efficiency}

The feasible allocation $x^{*}$ is constrained myopic periodically (CMP) efficient if there is no allocation $\tilde{x}$ and no period $t^{\prime}$ such that

(i) $\tilde{x}_{t^{\prime}+1, T \mid t^{\prime}}^{h}=x_{t^{\prime}+1, T \mid t^{\prime}}^{* h}$ for every $h \in H$,

(ii) $\sum_{h \in H} \tilde{x}_{t^{\prime} \mid t^{\prime}}^{h}=\sum_{h \in H} e_{t^{\prime} \mid t^{\prime}}^{h}$

(iii) $\tilde{x}_{\cdot \mid t^{\prime}}^{h} \succeq_{-x_{-\mid t^{\prime}}^{* h}} x_{\cdot \mid t^{\prime}}^{* h}$ for all $h \in H$, and

(iv) $\tilde{x}_{\cdot \mid t^{\prime}}^{h^{\prime}} \succ_{x_{-\mid t^{\prime}}^{* h^{\prime}}} x_{\cdot \mid t^{\prime}}^{* h^{\prime}}$ for some $h^{\prime} \in H$.

The following theorem says that CMP efficiency is weaker than MOP efficiency. Its proof is obvious and is therefore omitted.

\section{Theorem 5.5}

If an allocation is MOP efficient, then it is CMP efficient.

A naïve equilibrium allocation is CMP efficient under the assumptions of the foregoing sections.

\section{Theorem 5.6}

In an economy $\mathcal{E}$ that satisfies Assumptions 2, 3, and 4, a naïve equilibrium allocation is CMP efficient.

As the next example shows, a sophisticated equilibrium allocation is not necessarily CMP efficient under Assumptions 2, 3, and 4.

\footnotetext{
${ }^{5}$ See for instance Geanakoplos and Polemarchakis (1986), Citanna, Kajii and Villanacci (1998) and Herings and Polemarchakis (2004).
} 


\section{Example 5.7}

Consider an economy with two sophisticated households, two commodities and two periods. Let the preferences of household 1 be given by

$$
\begin{aligned}
& u_{1}^{1}\left(x_{1 \mid 1}^{1}, x_{2 \mid 1}^{1}\right)=x_{1,1 \mid 1}^{1}+\frac{1}{4} x_{1,2 \mid 1}^{1}+x_{2,1 \mid 1}^{1}+\frac{1}{4} x_{2,2 \mid 1}^{1} \\
& u_{2}^{1}\left(x_{1 \mid 1}^{1}, x_{2 \mid 2}^{1}\right)=\left\{\begin{array}{lll}
x_{2,1 \mid 2}^{1}+\frac{1}{4} x_{2,2 \mid 2}^{1} & \text { if } \quad & x_{1,1 \mid 1}^{1} \leq 1 \\
\frac{1}{4} x_{2,1 \mid 2}^{1}+x_{2,2 \mid 2}^{1} & \text { if } \quad & x_{1,1 \mid 1}^{1}>1 .
\end{array}\right.
\end{aligned}
$$

Let the preferences of household 2 be given by

$$
\begin{aligned}
& u_{1}^{2}\left(x_{1 \mid 1}^{2}, x_{2 \mid 1}^{2}\right)=\frac{1}{4} x_{1,1 \mid 1}^{2}+x_{1,2 \mid 1}^{2}+\frac{1}{4} x_{2,1 \mid 1}^{2}+x_{2,2 \mid 1}^{2} \\
& u_{2}^{2}\left(x_{1 \mid 1}^{2}, x_{2 \mid 2}^{2}\right)= \begin{cases}\frac{1}{4} x_{2,1 \mid 2}^{2}+x_{2,2 \mid 2}^{2} & \text { if } \quad x_{1,2 \mid 1}^{2} \leq 1 \\
x_{2,1 \mid 2}^{2}+\frac{1}{4} x_{2,2 \mid 2}^{2} & \text { if } \quad x_{1,2 \mid 1}^{2}>1 .\end{cases}
\end{aligned}
$$

Let the endowments be given by $e_{t, l \mid 1}^{h}=1$ for every good $l$, for every period $t$, and for every household $h$.

Consider prices and allocation $\left(p^{*}, x^{*}\right)$, where $p_{\tau, l \mid t}^{*}=1$ for every $l \in L$ and every $t, \tau \in T$ with $t \leq \tau, x_{\cdot \mid 1}^{* 1}=(1,1,2,0), x_{\cdot \mid 1}^{* 2}=(1,1,0,2), x_{\cdot \mid 2}^{* 1}=(2,0)$, and $x_{\cdot \mid 2}^{* 2}=(0,2)$. It can easily be seen that the pair $\left(p^{*}, x^{*}\right)$ constitutes a sophisticated equilibrium.

However, consider the allocation $\tilde{x}$ where $\tilde{x}_{\cdot \mid 1}^{1}=(2,0,2,0), \tilde{x}_{\cdot \mid 1}^{2}=(0,2,0,2), \tilde{x}_{\cdot \mid 2}^{1}=$ $(2,0)$, and $\tilde{x}_{\cdot \mid 2}^{2}=(0,2)$. In the first period both households are better off. Therefore, the sophisticated equilibrium allocation $x^{*}$ is not CMP efficient.

By restricting the degree of time-inconsistency in such a way that consumption decisions do not depend on past consumption, a sophisticated equilibrium allocation is CMP efficient. This is shown in the following theorem.

\section{Theorem 5.8}

In an economy $\mathcal{E}$ that satisfies Assumptions 2, 3, 4, and 6, a sophisticated equilibrium allocation is CMP efficient.

Thus, if the degree of time-inconsistency is restricted in the sense of Assumption 6, then a sophisticated equilibrium is CMP efficient. Krussel, Kuruşçu, and Smith (2002) consider similar concepts as the ones used in this section, for economies with a representative consumer. 


\section{Efficiency - the Forward-looking Case}

In this section we consider social planners that care about all selves. A social planner will reallocate consumption only if by doing so he can make one self of one household better off, while not making any self of any household worse off. On the one hand we might expect social planners to have more opportunities to improve welfare now, in the sense that there are more selves to be made better off. On the other hand, social planners have less opportunities to improve welfare since preferences depend on past consumption. In the preceding section, a social planner was myopic and therefore allowed to make future selves worse off, but here this is no longer the case. Thus, there is no direct relationship between the concepts in this section and the concepts in the preceding section.

The modeling of forward-looking social planners requires an extension of the preferences of households. A reallocation of commodities in period $t$ affects households in periods $t+1$ and further. Such a reallocation will only be made if no current or future self is made worse off. If we want to check whether future selves will be worse off after the reallocation, we need households to be able to compare consumption bundles with different realized past consumption. In this subsection we will extend the preferences of a household $h$ in period $t$ to preferences with domain $X_{\cdot \mid 1}^{h}$. We denote these preferences by $\succeq^{* h, t}$ and impose the following restriction on them

$$
\begin{aligned}
\left(x_{-\mid t}^{h}, x_{\cdot \mid t}^{h}\right) & \succeq^{* h, t} \quad\left(x_{-\mid t}^{h}, \bar{x}_{\cdot \mid t}^{h}\right) \\
& \operatorname{iff} \\
x_{\cdot \mid t}^{h} & \succeq_{x_{-\mid t}^{h}} \quad \bar{x}_{\cdot \mid t}^{h}
\end{aligned}
$$

for $x_{\cdot \mid t}^{h}, \bar{x}_{\cdot \mid t}^{h} \in X_{\cdot \mid t}^{h}$ and $x_{-\mid t}^{h} \in X_{-\mid t}^{h}$. Notice that on top of comparing consumption bundles with identical past consumption, $\succeq^{* h, t}$ can also be used to compare consumption bundles with different past consumption. For all properties of preference relations $\succeq_{x_{-\mid t}^{h}}$ that we defined in the first part of this paper, we will say that $\succeq^{* h, t}$ satisfies these properties if the induced $\succeq_{x_{-\mid t}^{h}}$ satisfy them.

Some of our results require the following version of independence of preferences of past consumption.

\section{Definition 6.1 Strong independence of past consumption}

Preferences $\succeq^{* h, t}$ are strongly independent of past consumption if the following holds: $\left(\widehat{x}_{-\mid t}^{h}, \widehat{x}_{\cdot \mid t}^{h}\right) \succeq^{* h, t}\left(\bar{x}_{-\mid t}^{h}, \bar{x}_{\cdot \mid t}^{h}\right)$ if and only if $\left(x_{-\mid t}^{h}, \widehat{x}_{\cdot \mid t}^{h}\right) \succeq^{* h, t}\left(\breve{x}_{-\mid t}^{h}, \bar{x}_{\cdot \mid t}^{h}\right)$ for every $x_{-\mid t}^{h}, \breve{x}_{-\mid t}^{h} \in X_{-\mid t}^{h}$.

We replace Assumption 6 by Assumption 6'.

Ass. 6' Preferences $\succeq^{* h, t}$ are strongly independent of past consumption. 
This assumption is stronger than Assumption 6. Consider a household with preferences $\succeq^{* h, t}$ represented by $U\left(x_{-\mid t}^{h}, x_{\cdot \mid t}^{h}\right)=\sum_{t^{\prime}<t} \sum_{l \in L} x_{t^{\prime}, l \mid t^{\prime}}^{h}+\sum_{t^{\prime} \geq t} \sum_{l \in L} x_{t^{\prime}, l \mid t}^{h}$. These preferences do satisfy Assumption 6, but not Assumption 6'. With these specific preferences past consumption does not influence current behavior, but past consumption does influence current utility.

We will again first consider social planners that can alter both actual and planned consumption.

\subsection{Overall Pareto Efficiency}

In this subsection we consider social planners that can alter both current and planned consumption. Combined with the assumption that social planners care about all selves, the natural extension of the myopic overall Pareto efficiency concept yields the following definition.

\section{Definition 6.2 Overall Pareto (OP) Efficiency}

The feasible allocation $x^{*}$ is overall Pareto (OP) efficient if there is no allocation $\tilde{x}$ and no period $t^{\prime}$ such that

(i) $\sum_{h \in H} \tilde{x}_{\cdot \mid t}^{h}=\sum_{h \in H} e_{\cdot \mid t}^{h}$ for all $t \geq t^{\prime}$,

(ii) $\left(x_{-\mid t^{\prime}}^{* h}, \tilde{x}_{t^{\prime} \mid t^{\prime}}^{h}, \ldots, \tilde{x}_{t-1 \mid t-1}^{h}, \tilde{x}_{\cdot \mid t}^{h}\right) \succeq^{* h, t}\left(x_{-\mid t}^{* h}, x_{\cdot \mid t}^{* h}\right)$ for all $h \in H$ and all $t \geq t^{\prime}$, and

(iii) $\left(x_{-\mid t^{\prime}}^{* h^{\prime}}, \tilde{x}_{t^{\prime} \mid t^{\prime}}^{h^{\prime}}, \ldots, \tilde{x}_{t^{\prime \prime}-1 \mid t^{\prime \prime}-1}^{h^{\prime}}, \tilde{x}_{\cdot \mid t^{\prime \prime}}^{h^{\prime}}\right) \succ^{* h^{\prime}, t^{\prime \prime}}\left(x_{-\mid t^{\prime \prime}}^{* h^{\prime}}, x_{\cdot \mid t^{\prime \prime}}^{* h^{\prime}}\right)$ for some $h^{\prime} \in H$ and some $t^{\prime \prime} \geq t^{\prime}$.

A social planner will reallocate commodities only if by doing so one self of one household is made better off and no self of any household is made worse off. There is no need for a social planner to restrict himself to time-consistent allocations. This concept is therefore not appropriate for the analysis of sophisticated societies. If preferences do not depend on past consumption, OP efficiency corresponds to "weak Pareto efficiency" as discussed in Luttmer and Mariotti (2002). OP efficiency is indeed a weakening of Pareto efficiency.

\section{Theorem 6.3}

Assume that preferences are time-consistent and satisfy Assumption 6'. If a time-consistent allocation is Pareto efficient, then it is OP efficient.

Note that a time-consistent OP efficient allocation might not be Pareto efficient, even if preferences are time-consistent and satisfy Assumption 6'. Consider for instance an economy with two households, where one household has a much lower discount factor than the other. Consider an initial allocation where consumers have strictly positive endowments both in period 1 and in period 2. Then a social planner that cares only about the selves in 
the first period would let one household consume only in the first period and the other only in the second period. If the social planner would also have to take care of future selves of the households, this would not be possible. The household that would not consume in the second period would be better off in the first period, but worse off in the second period. Examples that show that naïve and sophisticated equilibrium allocations may not be OP efficient can easily be constructed.

In sophisticated societies, it makes sense to require a social planner to only change allocations in such a way that the reallocation is time-consistent. This is formalized in the following definition.

\section{Definition 6.4 TC Overall Pareto (TCOP) Efficiency}

The feasible time-consistent allocation $x^{*}$ is time-consistent overall Pareto (TCOP) efficient if there is no time-consistent allocation $\tilde{x}$ and no period $t^{\prime}$ such that

(i) $\sum_{h \in H} \tilde{x}_{\cdot \mid t}^{h}=\sum_{h \in H} e_{\cdot \mid t}^{h}$ for all $t \geq t^{\prime}$,

(ii) $\left(x_{-\mid t^{\prime}}^{* h}, \tilde{x}_{t^{\prime} \mid t^{\prime}}^{h}, \ldots, \tilde{x}_{t-1 \mid t-1}^{h}, \tilde{x}_{\cdot \mid t}^{h}\right) \succeq^{* h, t}\left(x_{-\mid t}^{* h}, x_{\cdot \mid t}^{* h}\right)$ for all $h \in H$ and all $t \geq t^{\prime}$, and

(iii) $\left(x_{-\mid t^{\prime}}^{* h^{\prime}}, \tilde{x}_{t^{\prime} \mid t^{\prime}}^{h^{\prime}}, \ldots, \tilde{x}_{t^{\prime \prime}-1 \mid t^{\prime \prime}-1}^{h^{\prime}}, \tilde{x}_{\cdot \mid t^{\prime \prime}}^{h}\right) \succ^{* h^{\prime}, t^{\prime \prime}}\left(x_{-\mid t^{\prime \prime}}^{* h^{\prime}}, x_{\cdot \mid t^{\prime \prime}}^{* h^{\prime}}\right)$ for some $h^{\prime} \in H$ and some $t^{\prime \prime} \geq t^{\prime}$.

In the case of myopic social planners we did not need to introduce a time-consistent version of MOP efficiency, since those social planners do not care about future selves. The following theorem provides a characterization TCOP efficiency, which is useful for later results. Its proof is obvious and therefore not included in the Appendix.

\section{Theorem 6.5}

A feasible time-consistent allocation $x^{*}$ is TCOP efficient if and only if there is no timeconsistent allocation $\tilde{x}$ and no period $t^{\prime}$ such that

(i) $\sum_{h \in H} \tilde{x}_{\cdot \mid 1}^{h}=\sum_{h \in H} e_{\cdot \mid 1}^{h}$,

(ii) $\left(x_{-\mid t^{\prime}}^{* h}, \tilde{x}_{\cdot \mid t^{\prime}}^{h}\right) \succeq^{* h, t} x_{\cdot \mid 1}^{* h}$ for all $h \in H$ and all $t \geq t^{\prime}$, and

(iii) $\left(x_{-\mid t^{\prime}}^{* h^{\prime}}, \tilde{x}_{\cdot \mid t^{\prime}}^{h^{\prime}}\right) \succ^{* h^{\prime}, t^{\prime \prime}} x_{\cdot 1}^{* h^{\prime}}$ for some $h^{\prime} \in H$ and some $t^{\prime \prime} \geq t^{\prime}$.

The following results shows that TCOP efficiency is a weakening of Pareto efficiency.

\section{Theorem 6.6}

Assume that preferences are time-consistent and satisfy Assumption 6'. If a time-consistent allocation is Pareto efficient then it is TCOP efficient. 
A similar argument as before shows that a TCOP efficient allocation might be Pareto inefficient.

The following theorem claims that if preferences are independent of past consumption, then a sophisticated equilibrium allocation is TCOP efficient.

\section{Theorem 6.7}

In an economy $\mathcal{E}$ that satisfies Assumptions 2, 3, 4, and 6', a sophisticated equilibrium allocation is TCOP efficient.

\subsection{Constrained Periodical Efficiency}

In this section we assume that social planners care about all selves, but that a social planner active in period $t$ can only modify consumption in period $t$. This yields the following definition.

\section{Definition 6.8 Constrained Periodical (CP) Efficiency}

The feasible allocation $x^{*}$ is constrained periodically (CP) efficient if there is no other allocation $\tilde{x}$ and no period $t^{\prime}$ such that

(i) $\tilde{x}_{t^{\prime}+1, T \mid t^{\prime}}^{h}=x_{t^{\prime}+1, T \mid t^{\prime}}^{* h}$ for every $h \in H$,

(ii) $\sum_{h \in H} \tilde{x}_{t^{\prime} \mid t^{\prime}}^{h}=\sum_{h \in H} e_{t^{\prime} \mid t^{\prime}}^{h}$

(iii) $\left(x_{-\mid t^{\prime}}^{* h}, \tilde{x}_{\cdot \mid t^{\prime}}^{h}\right) \succeq^{* h, t}\left(x_{-\mid t}^{* h}, x_{\cdot \mid t}^{* h}\right)$ for all $h \in H$ and all $t \geq t^{\prime}$, and

(iv) $\left(x_{-\mid t^{\prime}}^{* h^{\prime}}, \tilde{x}_{\cdot \mid t^{\prime}}^{h^{\prime}}\right) \succ^{* h^{\prime}, t^{\prime \prime}}\left(x_{-\mid t^{\prime \prime}}^{* h^{\prime}}, x_{\cdot \mid t^{\prime \prime}}^{* h^{\prime}}\right)$ for some $h^{\prime} \in H$ and some $t^{\prime \prime} \geq t^{\prime}$.

As only current consumption can be changed, it is not necessary to introduce a timeconsistent variant of this definition as we did in the foregoing section. Contrary to the concept of TCOP efficiency, the CP efficiency concept is also applicable to naïve societies.

The following theorem says that the CP efficiency concept is weaker than the OP efficiency concept. Since its proof is obvious, it is omitted.

\section{Theorem 6.9}

If an allocation is OP efficient, then it is CP efficient.

A similar theorem holds for time-consistent allocations and TCOP efficiency.

\section{Theorem 6.10}

If a time-consistent allocation is TCOP efficient, then it is CP efficient. 
Examples showing that under Assumptions 2, 3, 4, and 6, naïve and sophisticated equilibria need not be CP efficient, can easily be found by letting the utility level in the second period depend on first-period consumption. If preferences are strongly independent of the past, however, then naïve and sophisticated equilibria are constrained periodically efficient.

\section{Theorem 6.11}

In an economy $\mathcal{E}$ that satisfies Assumptions 2, 3, 4, and 6', naïve and sophisticated equilibrium allocations are CP efficient.

The results of the last two sections are summarized in the following two figures. An arrow from "A" to "B" means that A implies B. Labels attached to arrows specify under which assumptions the implications hold true.

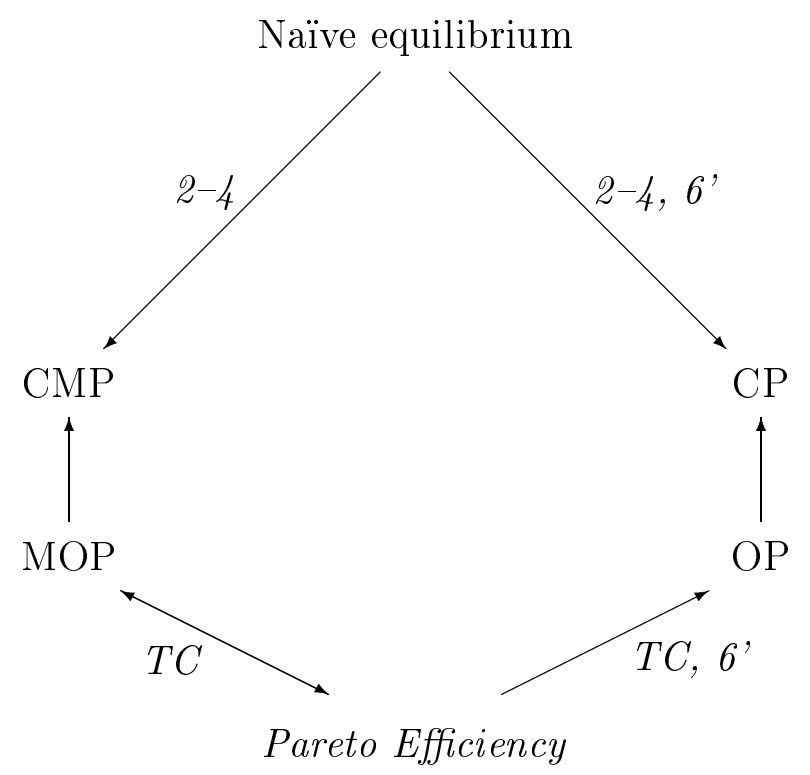

Figure 1: Naïve societies

\section{Conclusion}

In this paper, changing preferences are introduced in a multi-period general equilibrium model with incomplete markets. Time-inconsistent preferences lead to the development of new concepts of household behavior, equilibrium, and efficiency. A distinction is made between naïve and sophisticated societies. Appropriate equilibrium notions are defined. We 


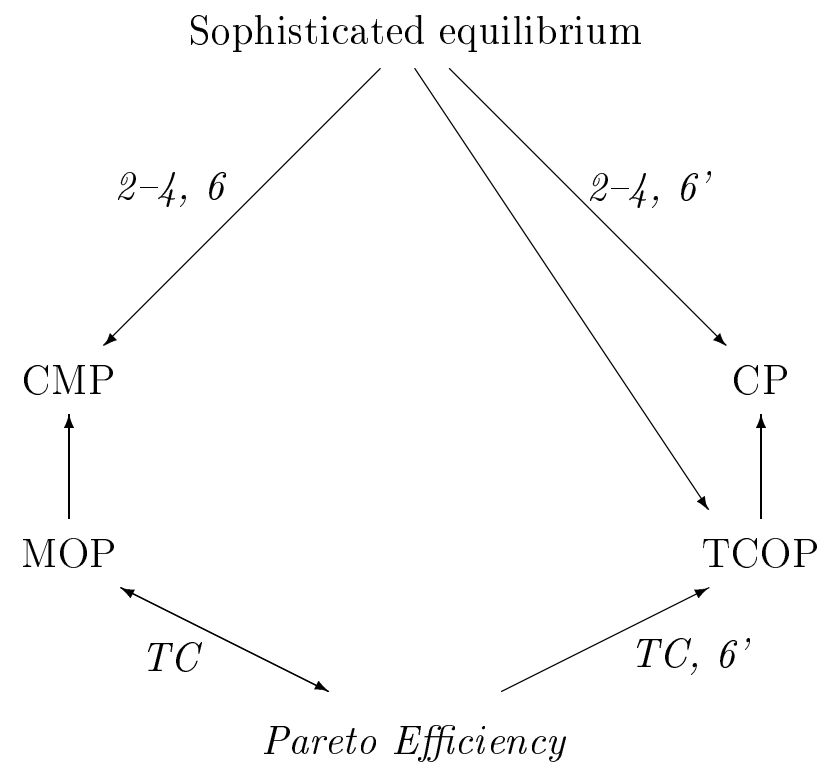

Figure 2: Sophisticated societies

extend the standard competitive equilibrium notion and call it an extended competitive equilibrium. It is shown that, in the case of time-consistent preferences, an extended competitive equilibrium is a naïve equilibrium and a sophisticated equilibrium coincides with an extended competitive equilibrium. An intriguing result is that with time-consistent preferences there can be naïve equilibrium allocations that are not compatible with any competitive equilibrium. For naïve societies an equilibrium is shown to exist under quite general conditions. For sophisticated societies the existence of an equilibrium can only be established when certain assumptions on the degree of time-inconsistency are made.

Several efficiency criteria are introduced. A distinction is made between efficiency concepts that take into account only the preferences of the current selves and concepts that take into account the preferences of both the current and future selves. Moreover, we distinguish the cases where only current consumption can be altered to make Pareto improvements and cases where both current and planned consumption can be changed. Suppose only current consumption can be altered. Then we provide sufficient conditions for both naïve and sophisticated equilibria to be efficient. Suppose both current and planned consumption can be changed. Then naïve equilibria are typically not efficient. If future selves are not taken into account, then sophisticated equilibria are not efficient either. For sophisticated equilibria we provide sufficient conditions for efficiency when future selves are taken into account. 


\section{Appendix}

\section{Lemma 2.3}

If the preferences of household $h$ are such that for every $x_{\cdot \mid 1}^{h}, \bar{x}_{\cdot \mid 1}^{h} \in X_{\cdot \mid 1}^{h}$ with $x_{\tau \mid 1}^{h}=\bar{x}_{\tau \mid 1}^{h}$, $\tau=1, \ldots, t-1$

$$
x_{\cdot \mid 1}^{h} \succeq^{h, 1} \bar{x}_{\cdot \mid 1}^{h} \text { if and only if } x_{t, T \mid 1}^{h} \succeq_{x_{1, t-1 \mid 1}^{h, t}}^{h} \bar{x}_{t, T \mid 1}^{h},
$$

then the preferences of household $h$ are time-consistent.

\section{Proof}

Let $x_{-\mid t}^{h} \in X_{-\mid t}^{h}$. We first show that when $x_{\cdot \mid t}^{h}, \bar{x}_{\cdot \mid t}^{h} \in X_{\cdot \mid t}^{h}$ are such that $x_{t, t^{\prime}-1 \mid t}^{h}=\bar{x}_{t, t^{\prime}-1 \mid t}^{h}$, then

$$
x_{\cdot \mid t}^{h} \succeq_{x_{-\mid t}^{h}}^{h, t} \quad \bar{x}_{\cdot \mid t}^{h}
$$

implies

$$
x_{t^{\prime}, T \mid t}^{h} \succeq_{\left(x_{-\mid t}^{h}, x_{t, t^{\prime}-1 \mid t}^{h}\right)}^{h, t^{\prime}} \quad \bar{x}_{t^{\prime}, T \mid t}^{h}
$$

If $x_{\cdot \mid t}^{h} \succeq_{x_{-\mid t}^{h}}^{h, t} \bar{x}_{\cdot \mid t}^{h}$, then it follows from the "if" part of the hypothesis of the lemma that

$$
\left(x_{-\mid t}^{h}, x_{\cdot \mid t}^{h}\right) \succeq^{h, 1}\left(x_{-\mid t}^{h}, \bar{x}_{\cdot \mid t}^{h}\right)
$$

The "only if" part of the hypothesis yields

$$
x_{t^{\prime}, T \mid t}^{h} \succeq_{\left(x_{-\mid t}^{h}, x_{t, t^{\prime}-1 \mid t}^{h}\right)}^{h,} \bar{x}_{t^{\prime}, T \mid t}^{h}
$$

The proof that

$$
x_{t^{\prime}, T \mid t}^{h} \succeq_{\left(x_{-\mid t}^{h}, x_{t, t^{\prime}-1 \mid t}^{h}\right)}^{h, t^{\prime}} \bar{x}_{t^{\prime}, T \mid t}^{h}
$$

implies

$$
x_{\cdot \mid t}^{h} \succeq_{x_{-\mid t}^{h}}^{h, t} \bar{x}_{\cdot \mid t}^{h}
$$

is similar.

Q.E.D.

\section{Theorem 3.4}

If preferences of all households are time-consistent, then an extended competitive equilibrium of the economy $\mathcal{E}$ is a naïve equilibrium.

Proof

Suppose $\left(p^{*}, x^{*}\right)$ is an extended competitive equilibrium. Since $x_{\tau \mid t}^{* h}=x_{\tau \mid 1}^{* h}$ for every $h$ and 
every $\tau \geq t$ and $\sum_{h \in H} x_{\cdot \mid 1}^{* h}=\sum_{h \in H} e_{\cdot \mid 1}^{h}$, it can easily be seen that (b) of Definition 3.3 is satisfied. It remains to be shown that Condition (a) of that definition is satisfied.

Notice that if $x_{\cdot \mid 1}^{* h} \in \gamma_{1}^{h}\left(p_{\cdot \mid 1}^{*}\right)$, then $x_{t, T \mid 1}^{* h} \in \gamma_{t}^{h}\left(p_{t, T \mid 1}^{*}\right)$. Moreover, for every $x_{\cdot \mid t}^{h} \in \gamma_{t}^{h}\left(p_{t, T \mid 1}^{*}\right)$ there is $x_{\cdot \mid 1}^{h} \in \gamma_{1}^{h}\left(p_{\cdot \mid 1}^{*}\right)$ with $x_{t, T \mid 1}^{h}=x_{\cdot \mid t}^{h}$ and $x_{1, t-1 \mid 1}^{h}=x_{1, t-1 \mid 1}^{* h}$.

We know that $x_{\cdot \mid 1}^{* h} \in \delta_{1}^{h}\left(p_{\cdot \mid 1}^{*}\right)$. Thus, $x_{\cdot \mid 1}^{* h} \in \gamma_{1}^{h}\left(p_{\cdot \mid 1}^{*}\right)$ and $x_{\cdot \mid 1}^{* h} \succeq^{h, 1} x_{\cdot \mid 1}^{h}$ for all $x_{\cdot \mid 1}^{h} \in \gamma_{1}^{h}\left(p_{\cdot \mid 1}^{*}\right)$. Then, by time-consistency of preferences, $x_{t, T \mid 1}^{* h} \succeq_{x_{1, t-1 \mid 1}^{* h}}^{h, t} x_{\cdot \mid t}^{h}$ for all $x_{\cdot \mid t}^{h} \in \gamma_{t}^{h}\left(p_{t, T \mid 1}^{*}\right)$, so $x_{t, T \mid 1}^{* h} \in \delta_{t}^{h}\left(p_{t, T \mid 1}^{*}, x_{1, t-1 \mid 1}^{* h}\right)=\delta_{t}^{h}\left(p_{\cdot \mid t}^{*}, x_{-\mid t}^{* h}\right)$. Thus, the extended competitive equilibrium is a naïve equilibrium.

Q.E.D.

\section{Theorem 3.6}

Assume that preferences are time-consistent. If a naïve equilibrium exists in the economy $\mathcal{E}$, then also an extended competitive equilibrium exists.

\section{Proof}

Let $\left(p^{*}, x^{*}\right)$ be a naïve equilibrium. Then we know that $x_{t, T \mid 1}^{* h} \in \gamma_{t}^{h}\left(p_{t, T \mid 1}^{*}\right)$. Furthermore, $\left(x_{1, t-1 \mid 1}^{* h}, x_{t, T \mid 1}^{* h}\right) \succeq^{h, 1}\left(x_{1, t-1 \mid 1}^{* h}, x_{t, T \mid 1}^{h}\right)$ for all $x_{t, T \mid 1}^{h} \in \gamma_{t}^{h}\left(p_{t, T \mid 1}^{*}\right)$.

By time-consistency of preferences we have $x_{t, T \mid 1}^{* h} \succeq_{x_{1, t-1 \mid 1}^{* h, t}}^{h h} x_{t, T \mid 1}^{h}$ for all $x_{t, T \mid 1}^{h} \in \gamma_{t}^{h}\left(p_{t, T \mid 1}^{*}\right)$. Thus, $x_{t, T \mid 1}^{* h} \in \delta_{t}^{h}\left(p_{t, T \mid 1}^{*}, x_{1, t-1 \mid 1}^{* h}\right)$. Let $\widehat{p}$ and $\widehat{x}$ be defined by $\widehat{p}_{\cdot \mid t}=p_{t, T \mid 1}^{*}$ and $\widehat{x}_{\cdot \mid t}^{h}=x_{t, T \mid 1}^{* h}$. It then follows immediately that $(\widehat{p}, \widehat{x})$ is a naïve equilibrium.

Q.E.D.

\section{Theorem 3.7 (Existence of naïve equilibrium)}

If the economy $\mathcal{E}$ satisfies Assumptions $1-5$, then there exists a naive equilibrium $\left(p^{*}, x^{*}\right)$.

\section{Proof}

We follow the approach of Debreu (1959) compounded with an induction argument.

First, let $\varepsilon>0$ and define

$$
\widehat{X}_{\tau \mid t}^{h}=\left\{x_{\tau \mid t}^{h} \in X_{\tau \mid t}^{h} \mid x_{\tau, l \mid t}^{h} \leq \sum_{h \in H} e_{\tau, l \mid t}^{h}+\varepsilon \text { for all } l \in L\right\}
$$

for some $\varepsilon>0$. Let $\widehat{\gamma}_{t}^{h}$ and $\widehat{\delta}_{t}^{h}$ denote the corresponding budget and demand correspondences. The economy $\widehat{\mathcal{E}}$ is the compactified economy. We derive some properties of the demand correspondence $\widehat{\delta}^{h}$.

We denote the $(L-1)$-dimensional unit simplex by $\Delta$, so $\Delta=\left\{p \in \mathbb{R}_{+}^{L} \mid \sum_{l=1}^{L} p_{l}=1\right\}$, and we denote the $k$-fold Cartesian product of $\Delta$ by $\Delta^{k}$. The price vectors are restricted to the sets $\widehat{P}_{\mid t}=\Delta^{T-t+1}$.

In the next lemma the box product in $p_{t} \square \delta_{t}^{h}\left(p_{\cdot \mid t}, x_{-\mid t}^{h}\right)$ is defined by taking for all $\tau \geq t$ the product of $p_{\tau \mid t}$ and any demand $x_{\tau \mid t}^{h}$ planned at period $t$ for period $\tau$, i.e.

$$
\begin{aligned}
p_{\cdot \mid t} \square \delta_{t}^{h}\left(p_{\cdot \mid t}, x_{-\mid t}^{h}\right)=\left\{\left(w_{t}, \ldots, w_{T}\right) \in \mathbb{R}^{T-t+1} \quad\right. & \text { there is an } x_{\cdot \mid t}^{h} \in \delta_{t}^{h}\left(p_{\cdot \mid t}, x_{-\mid t}^{h}\right) \\
& \text { such that } \left.w_{\tau}=p_{\tau \mid t} x_{\tau \mid t}^{h}, \tau \in t, \ldots, T\right\} .
\end{aligned}
$$




\section{Lemma 8.1}

Assume that the economy $\mathcal{E}$ satisfies Assumptions 1-5. Consider a naïve household $h \in H$, a planning period $t \in T$, and a realized consumption plan $x_{-\mid t}^{h} \in \widehat{X}_{-\mid t}^{h}$. Then, at prices $p_{\cdot \mid t} \in \widehat{P}_{\cdot \mid t}, \widehat{\delta}_{t}^{h}\left(\cdot, x_{-\mid t}^{h}\right)$ is a non-empty, compact and convex-valued, upper-hemi continuous correspondence that satisfies:

- Walras' law, $p_{\cdot \mid t} \square \widehat{\delta}_{t}^{h}\left(p_{\cdot \mid t}, x_{-\mid t}^{h}\right)=\left\{p_{t \mid t} e_{t \mid t}^{h}, \ldots, p_{T \mid t} e_{T \mid t}^{h}\right\}$,

- Homogeneity property, $\widehat{\delta}_{t}^{h}\left(p_{\cdot \mid t}, x_{-\mid t}^{h}\right)=\widehat{\delta}_{t}^{h}\left(\bar{p}_{\cdot \mid t}, x_{-\mid t}^{h}\right)$, where for $\tau^{\prime} \geq t$, for $\lambda>0$, $\bar{p}_{\tau^{\prime} \mid t}=\lambda p_{\tau^{\prime} \mid t}$ and $\bar{p}_{\tau \mid t}=p_{\tau \mid t}$ for $\tau \neq \tau^{\prime}$.

\section{Proof}

(i) Since $e_{\cdot \mid t}^{h} \in \widehat{\gamma}_{t}^{h}\left(p_{\cdot \mid t}\right)$, we know that $\widehat{\gamma}_{t}^{h}\left(p_{\cdot \mid t}\right)$ is non-empty.

(ii) Consider a sequence $\left\{p_{\cdot \mid t}\right\}_{m=1}^{\infty}$ with $p_{\cdot \mid t}^{m} \rightarrow p_{\cdot \mid t}$. Let the sequence $\left\{x_{\cdot \mid t}^{h}\right\}_{m=1}^{m}$ be such that $x_{\cdot \mid t}^{h} \in \widehat{\gamma}_{t}^{h}\left(p_{\cdot \mid t}{ }^{m}\right)$ for every $m$ and $x_{\cdot \mid t}^{h} \rightarrow x_{\cdot \mid t}^{h}$. By closedness of $\widehat{X}_{\cdot \mid t}^{h}$ and since $p_{\tau \mid t}{ }^{m} x_{\tau \mid t}^{h}{ }^{m} \leq p_{\tau \mid t}{ }^{m} e_{\tau \mid t}^{h}$, it follows that $x_{\cdot \mid t}^{h} \in \widehat{\gamma}_{t}^{h}\left(p_{\cdot \mid t}\right)$. Since $\widehat{\gamma}_{t}^{h}$ is bounded, it follows that $\widehat{\gamma}_{t}^{h}$ is upper-hemi continuous.

(iii) Let $\left\{p_{\cdot \mid t}{ }^{m}\right\}_{m=1}^{\infty}$ be a sequence of prices with $p_{\cdot \mid t}{ }^{m} \rightarrow p_{\cdot \mid t}$. Let $x_{\cdot \mid t}^{h} \in \widehat{\gamma}_{t}^{h}\left(p_{\cdot \mid t}\right)$. Then $p_{\tau \mid t} x_{\tau \mid t}^{h} \leq p_{\tau \mid t} e_{\tau \mid t}^{h}$. Define $a^{\tau m} \in \mathbb{R}_{++}$such that $p_{\tau \mid t}{ }^{m} a^{\tau m} x_{\tau \mid t}^{h}=p_{\tau \mid t} e_{\tau \mid t}^{h}$.

If $p_{\tau \mid t} x_{\tau \mid t}^{h}<p_{\tau \mid t} e_{\tau \mid t}^{h}$, then $p_{\tau \mid t}{ }^{m} x_{\tau \mid t}^{h} \leq p_{\tau \mid t} e_{\tau \mid t}^{h}$ for $m$ larger than a certain value $M^{1}$. In that case define $x_{\tau \mid t}^{h}{ }^{m}=x_{\tau \mid t}^{h}$ for $m>M^{1}$.

Otherwise, if $p_{\tau \mid t} x_{\tau \mid t}^{h}=p_{\tau \mid t} e_{\tau \mid t}^{h}>0$, it holds that $p_{\tau \mid t}{ }^{m} e_{\tau \mid t}^{h}>0$ and $p_{\tau \mid t}{ }^{m} x_{\tau \mid t}^{h}>0$ for $m$ larger than a certain $M^{2}$. Now, if $a^{\tau m}>1$, then define $x_{\tau \mid t}^{h}=x_{\tau \mid t}^{h}$ and if $a^{\tau m} \leq 1$, then define $x_{\tau \mid t}^{h}{ }^{m}=a^{\tau m} x_{\tau \mid t}^{h}$ for $m$ larger than $M^{2}$. Note that in this case $a^{\tau m}$ is unique and tends to one, since $a^{\tau m}=p_{\tau \mid t} e_{\tau \mid t}^{h} / p_{\tau \mid t}{ }^{m} x_{\tau \mid t}^{h}>0$.

For all $m$ smaller than or equal to $M^{1}$ or $M^{2}$ define $x_{\cdot \mid t}^{h}$ arbitrarily such that $x_{\cdot \mid t}^{h} \in$ $\widehat{\gamma}_{t}^{h}\left(p_{\cdot \mid t}^{m}\right)$.

Then $x_{\cdot \mid t}^{h} \in \widehat{\gamma}_{t}^{h}\left(p_{\cdot \mid t}{ }^{m}\right)$ for every $m$ and $x_{\cdot \mid t}^{h}{ }^{m} \rightarrow x_{\cdot \mid t}^{h}$. Thus, $\widehat{\gamma}_{t}^{h}$ is lower-hemi continuous. It follows that $\widehat{\gamma}_{t}^{h}$ is continuous.

We can then apply the Theorem of the Maximum to establish that $\widehat{\delta}_{t}^{h}\left(\cdot, x_{-\mid t}^{h}\right)$ is nonempty, compact-valued and upper-hemi continuous.

Convex-valuedness of $\widehat{\delta}_{t}^{h}$ is straightforward. Walras' law follows from monotonicity. The homogeneity property follows immediately from the definition of the budget constraints $\widehat{\gamma}_{t}^{h}$.

Q.E.D.

\section{Proof of Theorem 3.7 (continued)}

Define $\widehat{Z}_{\cdot \mid t}=\sum_{h \in H} \widehat{X}_{\cdot \mid t}^{h}-\sum_{h \in H}\left\{e_{\cdot \mid t}^{h}\right\}$ and for any $x_{-\mid t} \in \widehat{X}_{-\mid t}$, $\widehat{\zeta}_{t}\left(p_{\cdot \mid t}, x_{-\mid t}\right)=\sum_{h \in H} \widehat{\delta}_{t}^{h}\left(p_{\cdot \mid t}, x_{-\mid t}^{h}\right)-\sum_{h \in H}\left\{e_{\cdot \mid t}^{h}\right\}$. Using Lemma 8.1, the correspondence $\widehat{\zeta}_{t}\left(\cdot, x_{-\mid t}\right)$ is non-empty, compact-valued, convex-valued and upper-hemi continuous on $\widehat{P}_{\cdot \mid t}$. 
Define $\mu_{t}\left(z_{\cdot \mid t}\right)=\left\{\tilde{p}_{\cdot \mid t} \in \widehat{P}_{\cdot \mid t} \mid \tilde{p}_{\tau \mid t} z_{\tau \mid t} \geq p_{\tau \mid t} z_{\tau \mid t}\right.$ for all $p_{\cdot \mid t} \in \widehat{P}_{\cdot \mid t}$ for all $\left.\tau \geq t\right\}$. By the theorem of the maximum, $\mu_{t}$ is non-empty and upper-hemi continuous. Moreover, $\mu_{t}$ is convex-valued. For $x_{-\mid t} \in \widehat{X}_{-\mid t}$, define $\phi_{t}\left(\cdot, x_{-\mid t}\right): \widehat{P}_{t} \times \widehat{Z}_{t} \rightarrow \widehat{P}_{t} \times \widehat{Z}_{t}$ as $\phi_{t}\left(p_{\cdot \mid t}, z_{\cdot \mid t}, x_{-\mid t}\right)=$ $\mu_{t}\left(z_{\cdot \mid t}\right) \times \widehat{\zeta}_{t}\left(p_{\cdot \mid t}, x_{-\mid t}\right)$.

First, consider period 1. By Kakutani's fixed point theorem $\phi_{1}(\cdot)$ has a fixed point $\left(p_{\cdot \mid 1}^{*}, \bar{z}_{\cdot \mid 1}\right) \in \mu_{1}\left(\bar{z}_{\cdot \mid 1}\right) \times \widehat{\zeta}_{\cdot \mid 1}\left(p_{\cdot \mid t}^{*}\right)$.

Since then $p_{\tau \mid 1}^{*} \bar{z}_{\tau \mid 1} \leq 0$ for every $\tau$, we know, by the definition of $\mu_{1}$, that $\bar{z}_{\cdot \mid 1} \leq 0$. The corresponding consumption bundles are denoted by $\bar{x}_{\cdot \mid 1}^{h} \in \widehat{\delta}_{1}^{h}\left(p_{\cdot \mid 1}^{*}\right)$.

By Walras' law (Lemma 8.1), we know that $p_{\tau, l \mid 1}^{*}=0$ if $\bar{z}_{\tau, l \mid 1}<0$. By monotonicity, the excess supply of good $l$ for period $\tau$ can be given to any household without making that household worse off and without violating the budget constraints. Thus, given prices $p_{\cdot \mid 1}^{*}$, $z_{\cdot \mid 1}^{*}=0 \in \widehat{\zeta}_{1}\left(p_{\cdot \mid 1}^{*}\right)$. Denote the corresponding demands by $x_{\cdot \mid 1}^{* h}$.

It remains to be shown that $x_{\cdot \mid 1}^{* h} \in \delta_{1}^{h}\left(p_{\cdot \mid 1}^{*}\right)$ for every $h$. Suppose that this is not the case, i.e. suppose that there is a household $h$ with $x_{\cdot \mid 1}^{* h} \notin \delta_{1}^{h}\left(p_{\cdot \mid 1}^{*}\right)$. That would mean that there is an $\tilde{x}_{\cdot \mid 1}^{h} \in \delta_{1}^{h}\left(p_{\cdot \mid 1}^{*}\right)$ with $\tilde{x}_{\cdot \mid 1}^{h} \succ^{h, 1} x_{\cdot \mid 1}^{* h}$. Since $x_{\tau, l \mid 1}^{* h}<\sum_{h \in H} e_{\tau, l \mid 1}^{h}+\varepsilon$ for every $\tau$, and every $l$, there would be a small positive number $\lambda \in(0,1)$ such that $\lambda \tilde{x}_{\cdot \mid 1}^{h}+(1-\lambda) x_{\cdot \mid 1}^{* h} \in \widehat{\gamma}_{1}^{h}\left(p_{\cdot \mid 1}^{*}\right)$, and $\lambda \tilde{x}_{\cdot \mid 1}^{h}+(1-\lambda) x_{\cdot \mid 1}^{* h} \succ^{h, 1} x_{\cdot \mid 1}^{* h}$, which would contradict $x_{\cdot \mid 1}^{* h} \in \widehat{\delta}_{1}^{h}\left(p_{\cdot \mid 1}^{*}\right)$. Thus, $x_{\cdot \mid 1}^{* h} \in \delta_{1}^{h}\left(p_{\cdot \mid 1}^{*}\right)$ for every $h$.

Now suppose that for every $\tau \leq t$ there exist $p_{\cdot \mid \tau}^{*}$ such that $0 \in \zeta_{\tau}\left(p_{\cdot \mid \tau}^{*}, x_{-\mid \tau}^{*}\right)$. Then, by a similar argument as before it can be shown that there exists a $p_{\cdot \mid t+1}^{*}$ such that $0 \in$ $\zeta_{t+1}\left(p_{\cdot \mid t+1}^{*}, x_{-\mid t+1}^{*}\right)$. This argument of induction then establishes the existence of a naïve equilibrium.

Q.E.D.

\section{Theorem 4.2}

A pair $\left(p^{*}, x^{*}\right) \in P \times X$ is a sophisticated equilibrium if and only if it satisfies the following conditions:

(i) $x_{\cdot \mid 1}^{* h} \in \xi_{1}^{h}\left(p_{\cdot \mid 1}^{*}\right)$ for all $h \in H$,

(ii) $\sum_{h \in H} x_{\cdot \mid 1}^{* h}=\sum_{h \in H} e_{\cdot \mid 1}^{h}$ for all $h \in H$,

(iii) $p_{\cdot \mid t}^{*}=p_{t, T \mid 1}^{*}$ for all $t \in T$,

(iv) $x_{\cdot \mid t}^{* h}=x_{t, T \mid 1}^{* h}$ for all $h \in H$ and all $t \in T$.

\section{Proof}

It can immediately be seen that a sophisticated equilibrium pair $\left(p^{*}, x^{*}\right)$ satisfies (i)-(iv). It remains to be shown that a pair that satisfies (i)-(iv) is a sophisticated equilibrium. Let $\left(p^{*}, x^{*}\right)$ satisfy (i)-(iv) and let $t<t^{\prime}$. Then, by (iii) $p_{\cdot \mid t}^{*}=p_{t, T \mid 1}^{*}$ and $p_{\cdot \mid t^{\prime}}^{*}=p_{t^{\prime}, T \mid 1}^{*}$. So $p_{t^{\prime}, T \mid t}^{*}=p_{\cdot \mid t^{\prime}}^{*}$ and (c) is satisfied. Furthermore, $x_{\cdot \mid t}^{*}=x_{t, T \mid 1}^{*}$ and $x_{\cdot \mid t^{\prime}}^{*}=x_{t^{\prime}, T \mid 1}^{*}$. So $x_{t^{\prime}, T \mid t}^{*}=x_{\cdot \mid t^{\prime}}^{*}$ and (d) is satisfied. It also holds that $\sum_{h \in H} x_{\cdot \mid t}^{* h}=\sum_{h \in H} x_{t, T \mid 1}^{* h}=\sum_{h \in H} e_{t, T \mid 1}^{h}=\sum_{h \in H} e_{\cdot \mid t}^{h}$, 
so (b) is satisfied. Finally, $x_{\cdot \mid 1}^{* h} \in \xi_{1}^{h}\left(p_{\cdot \mid 1}^{*}\right)$, so $x_{\cdot \mid 1}^{* h} \in \phi_{1}^{h}\left(p_{\cdot \mid 1}^{*}\right)$, which implies that $x_{2, T \mid 1}^{* h} \in$ $\xi_{2}^{h}\left(p_{2, T \mid 1}^{*}, x_{1 \mid 1}^{* h}\right)$. But then, $x_{\cdot \mid 2}^{* h} \in \xi_{2}^{h}\left(p_{\cdot \mid 2}^{*}, x_{1 \mid 1}^{* h}\right)$. Now, by an argument of induction it can be shown that $x_{\cdot \mid t}^{* h} \in \xi_{t}^{h}\left(p_{\cdot \mid t}^{*}, x_{-\mid t}^{* h}\right)$ for all t. So (a) is satisfied too. Thus, a pair $\left(p^{*}, x^{*}\right)$ that satisfies (i)-(iv) is a sophisticated equilibrium.

Q.E.D.

\section{Theorem 4.3}

Assume that the preferences of all households are time-consistent and that Assumptions 12 hold. A pair $\left(p^{*}, x^{*}\right) \in P \times X$ with $p^{*} \gg 0$ is a sophisticated equilibrium of the economy $\mathcal{E}$ if and only if it is an extended competitive equilibrium.

\section{Proof}

First of all, let $\left(p^{*}, x^{*}\right)$ be an extended competitive equilibrium. Since $x_{\cdot \mid 1}^{* h} \in \delta_{1}^{h}\left(p_{\cdot \mid 1}^{*}\right)$ we know that $x_{\cdot \mid 1}^{* h} \succeq^{h, 1} x_{\cdot \mid 1}^{h}$ for every $x_{\cdot \mid 1}^{h} \in X_{\cdot \mid 1}^{h}$ with $p_{\tau \mid 1}^{*} x_{\tau \mid 1}^{h} \leq p_{\tau \mid 1}^{*} e_{\tau \mid 1}^{h}$ for every $\tau$. By time-consistency we then know that $x_{T \mid 1}^{* h} \succeq_{x_{1, T-1 \mid 1}^{* h}}^{h, T} x_{T \mid 1}^{h}$ for every $x_{T \mid 1}^{h} \in X_{\cdot \mid T}^{h}$ with $p_{T \mid 1}^{*} x_{T \mid 1}^{h} \leq p_{T \mid 1}^{*} e_{T \mid 1}^{h}$. It follows that $x_{T \mid 1}^{* h} \in \xi_{T}^{h}\left(p_{T \mid 1}^{*}, x_{1, T-1 \mid 1}^{* h}\right)$. We show next that $x_{t, T \mid 1}^{* h} \in$ $\xi_{t}^{h}\left(p_{t, T \mid 1}^{*}, x_{1, t-1 \mid 1}^{* h}\right)$ for every $t$. Assume that $x_{\tau, T \mid 1}^{* h} \in \xi_{\tau}^{h}\left(p_{\tau, T \mid 1}^{*}, x_{1, \tau-1 \mid 1}^{* h}\right)$ for every $\tau>t$. Suppose that $x_{t, T \mid 1}^{* h} \notin \xi_{t}^{h}\left(p_{t, T \mid 1}^{*}, x_{1, t-1 \mid 1}^{* h}\right)$. Then there must be a consumption bundle that is strictly preferred to $x_{t, T \mid 1}^{* h}$, but is in the opportunity set at time $t$, which, by timeconsistency, leads to a contradiction of $x_{\cdot \mid 1}^{* h}$ being an optimal consumption bundle for household $h$ in period 1. Thus, $\left(p^{*}, x^{*}\right)$ is a sophisticated equilibrium.

Now let $\left(p^{*}, x^{*}\right)$ be a sophisticated equilibrium. Suppose that $\left(p^{*}, x^{*}\right)$ is not an extended competitive equilibrium. Then there must be a household $h$ and an $\widehat{x}_{\cdot \mid 1}^{h} \in X_{\cdot \mid 1}^{h}$ such that $\widehat{x}_{\cdot \mid 1}^{h} \succ^{h, 1} x_{\cdot \mid 1}^{* h}$ with $p_{\tau \mid 1}^{*} \widehat{x}_{\tau \mid 1}^{h} \leq p_{\tau \mid 1}^{*} e_{\tau \mid 1}^{h}$ for every $\tau$. Consider the maximum of those $\widehat{x}_{\cdot \mid 1}^{h}$ with respect to $\succ^{h, 1}$. Such an $\widehat{x}_{\cdot \mid 1}^{h}$ exists because preferences are continuous. Since $\widehat{x}_{\cdot \mid 1}^{h}$ is not chosen by $h$, there must be a $t_{1}>1$ such that $\widehat{x}_{t_{1}, T \mid 1}^{h} \notin \xi_{t_{1}}^{h}\left(p_{t_{1}, T \mid 1}^{*}, \widehat{x}_{1, t_{1}-1 \mid 1}^{h}\right)$. So there must be a $t_{1}^{\prime} \geq t_{1}$ and an $\tilde{x}_{\cdot \mid t_{1}^{\prime}}^{h} \in X_{\cdot \mid t_{1}^{\prime}}^{h}$ such that $\tilde{x}_{\cdot \mid t_{1}^{\prime}}^{h} \succ_{\widehat{x}_{1, t_{1}^{\prime}-1 \mid 1}^{h}}^{h, t_{1}^{\prime}} \widehat{x}_{t_{1}^{\prime}, T \mid 1}^{h}$ and $p_{\tau \mid 1}^{*} \tilde{x}_{\tau \mid t_{1}^{\prime}}^{h} \leq p_{\tau \mid 1}^{*} e_{\tau \mid 1}^{h}$ for every $\tau \geq t_{1}^{\prime}$, and by time-consistency $\left(\widehat{x}_{1, t_{1}^{\prime}-1 \mid 1}^{h}, \tilde{x}_{\cdot \mid t_{1}^{\prime}}^{h}\right) \succ^{h, 1} \widehat{x}_{\cdot \mid 1}^{h} \succ^{h, 1} x_{\cdot \mid 1}^{* h}$, which contradicts our assumption on $\widehat{x}_{\cdot \mid 1}^{h}$.

Q.E.D.

\section{Theorem 4.5 Existence of sophisticated equilibrium}

If the economy $\mathcal{E}$ satisfies Assumptions 1-6 and 4', then there exists a sophisticated equilibrium $\left(p^{*}, x^{*}\right)$.

\section{Proof}

We will now prove the existence of sophisticated equilibria. The next lemma states that Assumptions 1-6 and 4' suffice to obtain convex-valued demand of sophisticated households. In particular, it is shown that demand is either empty or single-valued. The first step is again to compactify the consumption sets and examine the compactified economy $\widehat{\mathcal{E}}$. 


\section{Lemma 8.2}

Assume that the economy $\mathcal{E}$ satisfies Assumptions 1-6 and 4'. Consider a sophisticated household $h \in H$, a planning period $t \in T$, and a realized consumption plan $x_{-\mid t}^{h} \in X_{-\mid t}^{h}$. Then, at prices $p_{\cdot \mid t} \in P_{\cdot \mid t}, \xi_{t}^{h}\left(\cdot, x_{-\mid t}^{h}\right)$ is convex-valued and either empty or single-valued.

\section{Proof}

Since preferences are independent on past consumption, the demand correspondences will also be independent on past consumption. Therefore, the opportunity sets

$$
\begin{aligned}
& \phi_{t}^{h}\left(p_{\cdot \mid t}, x_{-\mid t}^{h}\right)=\left\{x_{\cdot \mid t}^{h} \in X_{\cdot \mid t}^{h} \mid\right. p_{\tau \mid t} x_{\tau \mid t}^{h} \\
& x_{t+1, T \mid t}^{h} \leq p_{\tau \mid t} e_{\tau \mid t}^{h} \quad \text { for all } \tau \geq t, \quad \text { and } \\
&\left.\xi_{t+1}^{h}\left(p_{t+1, T \mid t}, x_{-\mid t}^{h}, x_{t \mid t}^{h}\right)\right\}
\end{aligned}
$$

will be convex-valued. Then it is straightforward that the demand correspondences are convex-valued.

Suppose that a demand correspondence contains two elements. By convex-valuedness of the demand correspondence and by strict convexity of preferences this yields a contradiction. Thus, the demand correspondence is either empty or single-valued.

Q.E.D.

The next lemma shows that demand in the compactified economy satisfies standard properties needed to show existence.

\section{Lemma 8.3}

Assume that the economy $\mathcal{E}$ satisfies Assumptions 1-6, and 4'. Then, at prices $p_{\cdot \mid t} \in \widehat{P}_{\cdot \mid t}$, $\widehat{\xi}_{t}^{h}$ is a non-empty, compact-valued and continuous function that satisfies for every $h \in H$, $t \in T$ :

- Walras' law, $p_{\cdot \mid t} \square \widehat{\xi}_{t}^{h}\left(p_{\cdot \mid t}, x_{-\mid t}^{h}\right)=\left\{p_{t \mid t} e_{t \mid t}^{h}, \ldots, p_{T \mid t} e_{T \mid t}^{h}\right\}$,

- Homogeneity property, $\widehat{\xi}_{t}^{h}\left(p_{\cdot \mid t}, x_{-\mid t}^{h}\right)=\widehat{\xi}_{t}^{h}\left(\bar{p}_{\cdot \mid t}, x_{-\mid t}^{h}\right)$, where for $\tau^{\prime} \geq t$, for $\lambda>0$, $\bar{p}_{\tau^{\prime} \mid t}=\lambda p_{\tau^{\prime} \mid t}$ and $\bar{p}_{\tau \mid t}=p_{\tau \mid t}$ for $\tau \neq \tau^{\prime}$.

\section{Proof}

The homogeneity property is straightforward.

Since in the last period the maximization problem for the sophisticated household is identical to that of the naïve household and since $\widehat{\phi}_{T}^{h}\left(p_{\cdot \mid T}, x_{-\mid T}^{h}\right)$ is independent of $x_{-\mid T}^{h}$, the characteristics of $\widehat{\xi}_{T}^{h}$ follow immediately from Lemma 8.1. By single-valuedness and upperhemi continuity, continuity of $\widehat{\xi}_{T}^{h}$ follows immediately. We will establish the properties of the other demand correspondences by an argument of backwards induction.

Let $t \in T$. Assume that $\widehat{\xi}_{\tau}^{h}$ is non-empty, compact-valued and continuous for $\tau \in$ $T, \tau \geq t+1$. We need to show that $\widehat{\xi}_{t}^{h}$ is non-empty, compact-valued and upper-hemi 
continuous. Thus, it is necessary to show that $\widehat{\phi}_{t}^{h}$ satisfies the conditions needed to apply the theorem of the maximum.

(i) Since $\widehat{\xi}_{t+1}^{h}\left(p_{\cdot \mid t+1}, x_{-\mid t}^{h}, e_{t \mid 1}^{h}\right)$ is non-empty, $p_{t \mid t} e_{t \mid 1}^{h} \leq p_{t \mid t} e_{t \mid 1}^{h}$, and $p_{\tau \mid t} x_{\tau \mid t}^{h} \leq p_{\tau \mid t} e_{\tau \mid 1}^{h}, \tau \geq$ $t+1$ for $x_{t+1, T \mid t}^{h}=\widehat{\xi}_{t+1}^{h}\left(p_{\cdot \mid t+1}, x_{-\mid t}^{h}, e_{t \mid 1}^{h}\right)$, it can be seen that $\left(e_{t \mid 1}^{h}, \widehat{\xi}_{t+1}^{h}\left(p_{\cdot \mid t+1}, x_{-\mid t}^{h}, e_{t \mid 1}^{h}\right)\right) \in$ $\widehat{\phi}_{t}^{h}\left(p_{\cdot \mid t}, x_{-\mid t}^{h}\right)$. Thus, $\widehat{\phi}_{t}^{h}\left(p_{\cdot \mid t}, x_{-\mid t}^{h}\right)$ is non-empty.

(ii) Consider the sequence $\left\{p_{\cdot \mid t}{ }^{m}\right\}_{m=1}^{\infty}$ with $p_{\cdot \mid t}{ }^{m} \rightarrow p_{\cdot \mid t}$. Let $\left\{x_{-\mid t}^{h}, x_{\cdot \mid t}^{h}\right\}_{m=1}^{\infty}$ be a sequence of consumption plans converging to $\left(x_{-\mid t}^{h}, x_{\cdot \mid t}^{h}\right)$, where $x_{-\mid t}^{h}{ }^{m} \in X_{-\mid t}^{h}$ and $x_{\cdot \mid t}^{h} \in$ $\widehat{\phi}_{t}^{h}\left(p_{\cdot \mid t}{ }^{m}, x_{-\mid t}^{h}{ }^{m}\right)$ for all $m$. Then $p_{\tau \mid t}{ }^{m} x_{\tau \mid t}^{h}{ }^{m} \leq p_{\tau \mid t}{ }^{m} e_{\tau \mid t}^{h}$ for every $\tau \geq t$ and $x_{t+1, T \mid t}^{h}=$ $\widehat{\xi}_{t+1}^{h}\left(p_{t+1, T \mid t^{m}}{ }^{m}, x_{-\mid t}^{h}{ }^{m}, x_{t \mid t}^{h}{ }^{m}\right)$. By continuity it follows that $p_{\tau \mid t} x_{\tau \mid t}^{h} \leq p_{\tau \mid t} e_{\tau \mid t}^{h}$ for every $\tau \geq$ $t$. Moreover, by continuity of $\widehat{\xi}_{t+1}^{h}, x_{t+1, T \mid t}^{h}=\widehat{\xi}_{t+1}^{h}\left(p_{t+1, T \mid t}, x_{-\mid t}^{h}, x_{t \mid t}^{h}\right)$. Therefore, $x_{\cdot \mid t}^{h} \in$ $\widehat{\phi}_{t}^{h}\left(p_{\cdot \mid t}, x_{-\mid t}^{h}\right)$. Thus, the graph of $\widehat{\phi}_{t}^{h}$ is closed.

By boundedness of $\widehat{X}_{\cdot \mid t}^{h}$ it can easily be seen, for a compact set $B$, that $\widehat{\phi}_{t}^{h}(B)$ is bounded. Therefore, $\widehat{\phi}_{t}^{h}$ is upper-hemi continuous.

(iii) Consider a sequence $\left\{p_{\cdot \mid t}{ }^{m}, x_{-\mid t}^{h}{ }^{m}\right\}_{m=1}^{\infty}$ with $\left(p_{\cdot \mid t}{ }^{m}, x_{-\mid t}^{h}\right) \rightarrow\left(p_{\cdot \mid t}, x_{-\mid t}^{h}\right)$. Let $x_{\cdot \mid t}^{h} \in$ $\widehat{\phi}_{t}^{h}\left(p_{\cdot \mid t}, x_{-\mid t}^{h}\right)$. Then, for $m$ large enough, there are $x_{t \mid t}^{h} \in \widehat{X}_{t \mid t}^{h}$ such that $p_{t \mid t}{ }^{m} x_{t \mid t}^{h}{ }^{m} \leq p_{t \mid t}{ }^{m} e_{t \mid 1}^{h}$ and $x_{t \mid t}^{h}{ }^{m} \rightarrow x_{t \mid t}^{h}$. Let $x_{t+1, T \mid t}^{h}=\widehat{\xi}_{t+1}^{h}\left(p_{t+1, T \mid t^{m}}{ }^{m}, x_{-\mid t}^{h}{ }^{m}, x_{t \mid t}^{h}{ }^{m}\right)$. It follows immediately that $p_{\tau \mid t}{ }^{m} x_{\tau \mid t}^{h}{ }^{m} \leq p_{\tau \mid t}{ }^{m} e_{\tau \mid t}^{h}$ for $\tau \geq t+1$. Continuity of $\widehat{\xi}_{t+1}^{h}$ then implies that $x_{t+1, T \mid t}^{h} \rightarrow$ $\widehat{\xi}_{t+1}^{h}\left(p_{t+1, T \mid t}, x_{-\mid t}^{h}, x_{t \mid t}^{h}\right)=x_{t+1, T \mid t}^{h}$. Therefore, $x_{\cdot \mid t}^{h} \in \widehat{\phi}_{t}^{h}\left(p_{\cdot \mid t}{ }^{m}, x_{-\mid t}^{h}{ }^{m}\right)$ and $x_{\cdot \mid t}^{h}{ }^{m} \rightarrow x_{\cdot \mid t}^{h}$. Thus, $\widehat{\phi}_{t}^{h}(\cdot)$ is lower-hemi continuous.

Since $\widehat{\phi}_{t}^{h}$ is both upper-hemi and lower-hemi continuous, it is continuous.

To conclude, $\widehat{\phi}_{t}^{h}$ satisfies the conditions needed to apply the theorem of the maximum. Also, since Walras' law holds for period $t+1$, and since consumption in period $t$ does not influence the optimal consumption in period $t+1$, Walras' law holds for period $t$. The characteristics of $\widehat{\xi}_{t}^{h}$ then follow immediately.

Q.E.D

\section{Proof of Theorem 4.5 (continued)}

Note that in order to prove the existence of a sophisticated equilibrium, we can restrict ourselves to the first planning period. By similar arguments as in the foregoing section, there exists a restricted equilibrium pair $\left(p_{\cdot \mid 1}^{*}, z_{\cdot \mid 1}^{*}\right)$ such that $z_{\cdot \mid 1}^{*} \in \widehat{\zeta}_{1}\left(p_{\cdot \mid 1}^{*}\right)$ and $z_{\cdot \mid 1}^{*} \leq 0$. By monotonicity and strict convexity of preferences, it must be the case that $p_{\cdot \mid 1}^{*} \gg 0$. Therefore, and by Walras' law, it must hold that $z_{\cdot \mid 1}^{*}=0$. Denote the corresponding consumption bundles by $x_{\cdot \mid 1}^{* h}$. It remains to be shown that $x_{\cdot \mid 1}^{* h} \in \xi_{1}^{h}\left(p_{\cdot \mid 1}^{*}\right)$. Suppose that this is not the case. Then two cases can be distinguished. First assume that $x_{2, T \mid 1}^{* h} \in \xi_{2}^{h}\left(p_{2, T \mid 1}^{*}, x_{1 \mid 1}^{* h}\right)$. Then, since consumption in period 1 does not influence optimal consumption in period 2, a similar argument as in the proof of Theorem 3.7 leads to a contradiction. Now assume that $x_{2, T \mid 1}^{* h} \notin \xi_{2}^{h}\left(p_{2, T \mid 1}^{*}, x_{1 \mid 1}^{* h}\right)$. Then, either $x_{3, T \mid 1}^{* h} \in \xi_{3}^{h}\left(p_{3, T \mid 1}^{*}, x_{1,2 \mid 1}^{* h}\right)$, which again leads to a contradiction, or $x_{3, T \mid 1}^{* h} \notin \xi_{3}^{h}\left(p_{3, T \mid 1}^{*}, x_{1,2 \mid 1}^{* h}\right)$. Continuing in this way, we end up with 
$x_{T \mid 1}^{* h} \notin \xi_{T}^{h}\left(p_{T \mid 1}^{*} x_{1, T-1 \mid 1}^{* h}\right)$, which leads to a contraction by the same arguments as before. Thus, a sophisticated equilibrium exists.

Q.E.D.

\section{Theorem 5.3}

Assume that preferences are time-consistent. Then a time-consistent allocation is MOP efficient if and only if it is Pareto efficient.

\section{Proof}

Let the time-consistent allocation $x^{*}$ be Pareto efficient. Suppose that it is not MOP efficient. Then there must be an $\tilde{x}$ and a period $t^{\prime}$ such that

(i) $\sum_{h \in H} \tilde{x}_{\cdot \mid t^{\prime}}^{h}=\sum_{h \in H} e_{\cdot \mid t^{\prime}}^{h}$,

(ii) $\tilde{x}_{\cdot \mid t^{\prime}}^{h} \succeq_{x_{-\mid t^{\prime}}^{* h}} x_{\cdot \mid t^{\prime}}^{* h}$ for all $h \in H$, and

(iii) $\tilde{x}_{\cdot \mid t^{\prime}}^{h^{\prime}} \succ_{x_{-\mid t^{\prime}} h^{\prime}} x_{\cdot t^{\prime}}^{* h^{\prime}}$ for some $h^{\prime} \in H$.

But then, by time-consistency of preferences we have $\left(x_{-\mid t^{\prime}}^{* h}, \tilde{x}_{\cdot \mid t^{\prime}}^{h}\right) \succeq^{h, 1}\left(x_{-\mid t^{\prime}}^{* h}, x_{\cdot \mid t^{\prime}}^{* h}\right)$ for all $h \in H$, and $\left(x_{-\mid t^{\prime}}^{* h^{\prime}}, \tilde{x}_{\cdot \mid t^{\prime}}^{h^{\prime}}\right) \succ^{h^{\prime}, 1}\left(x_{-\mid t^{\prime}}^{* h^{\prime}}, x_{\cdot \mid t^{\prime}}^{* h^{\prime}}\right)$ for some $h^{\prime} \in H$. Then it follows from timeconsistency of $x^{*}$ that $\left(x_{-\mid t^{\prime}}^{* h}, \tilde{x}_{\cdot \mid t^{\prime}}^{h}\right) \succeq^{h, 1} x_{\cdot \mid 1}^{* h}$ for all $h \in H$, and $\left(x_{-\mid t^{\prime}}^{* h^{\prime}}, \tilde{x}_{\cdot \mid t^{\prime}}^{h^{\prime}}\right) \succ^{h^{\prime}, 1} x_{\cdot \mid 1}^{* h^{\prime}}$ for some $h^{\prime} \in H$. This yields a contradiction to $x^{*}$ being Pareto efficient.

That a MOP efficient allocation is Pareto efficient, follows immediately from the definitions.

Q.E.D.

\section{Theorem 5.6}

In an economy $\mathcal{E}$ that satisfies Assumptions 2, 3, and 4, a naïve equilibrium allocation is CMP efficient.

Proof

Let $\left(p^{*}, x^{*}\right)$ be a naïve equilibrium. Suppose that $x^{*}$ is not CMP efficient, i.e. that there is a reallocation $\tilde{x}$ and a period $t^{\prime}$ that satisfy

(i) $\tilde{x}_{t^{\prime}+1, T \mid t^{\prime}}^{h}=x_{t^{\prime}+1, T \mid t^{\prime}}^{* h}$ for every $h \in H$,

(ii) $\sum_{h \in H} \tilde{x}_{t^{\prime} \mid t^{\prime}}^{h}=\sum_{h \in H} e_{t^{\prime} \mid t^{\prime}}^{h}$

(iii) $\tilde{x}_{\cdot \mid t^{\prime}}^{h} \succeq_{-x_{-\mid t^{\prime}}^{* h}} x_{\cdot \mid t^{\prime}}^{* h}$ for all $h \in H$, and

(iv) $\tilde{x}_{\cdot \mid t^{\prime}}^{h^{\prime}} \succ_{x_{-\mid t^{\prime}}} x_{\cdot \mid t^{\prime}}^{* h^{\prime}}$ for some $h^{\prime} \in H$. 
Then, since $\tilde{x}_{\cdot \mid t^{\prime}}^{h}$ was not chosen in equilibrium, we must have

$$
\begin{aligned}
& p_{t^{\prime} \mid t^{\prime}}^{*} \tilde{x}_{t^{\prime} \mid t^{\prime}}^{h^{\prime}}>p_{t^{\prime} \mid t^{\prime}}^{*} x_{t^{\prime} \mid t^{\prime}}^{* h^{\prime}}, \text { and } \\
& p_{t^{\prime} \mid t^{\prime}}^{*} \tilde{x}_{t^{\prime} \mid t^{\prime}}^{h} \geq p_{t^{\prime} \mid t^{\prime}}^{*} x_{t^{\prime} \mid t^{\prime}}^{* h} \text { for every household } h \in H .
\end{aligned}
$$

By summing over all households, this leads to

$$
\sum_{h \in H} p_{t^{\prime} \mid t^{\prime}}^{*} \tilde{x}_{t^{\prime} \mid t^{\prime}}^{h}>\sum_{h \in H} p_{t^{\prime} \mid t^{\prime}}^{*} x_{t^{\prime} \mid t^{\prime}}^{* h}
$$

which can be written as

$$
p_{t^{\prime} \mid t^{\prime}}^{*} \sum_{h \in H} \tilde{x}_{t^{\prime} \mid t^{\prime}}^{h}>p_{t^{\prime} \mid t^{\prime}}^{*} \sum_{h \in H} x_{t^{\prime} \mid t^{\prime}}^{* h}
$$

This leads to a contradiction, since, by assumption, we have

$$
\sum_{h \in H} \tilde{x}_{t^{\prime} \mid t^{\prime}}^{h}=\sum_{h \in H} e_{t^{\prime} \mid 1}^{h}=\sum_{h \in H} x_{t^{\prime} \mid t^{\prime}}^{* h}
$$

Thus, it follows that the naïve equilibrium allocation $x^{*}$ must be CMP efficient.

Q.E.D.

\section{Theorem 5.8}

In an economy $\mathcal{E}$ that satisfies Assumptions 2, 3, 4, and 6, a sophisticated equilibrium allocation is CMP efficient.

\section{Proof}

Let $\left(p^{*}, x^{*}\right)$ be a sophisticated equilibrium. Suppose that $x^{*}$ is not CMP efficient. Then there must be a reallocation $\tilde{x}$ and a period $t^{\prime}$ that satisfy

(i) $\tilde{x}_{t^{\prime}+1, T \mid t^{\prime}}^{h}=x_{t^{\prime}+1, T \mid t^{\prime}}^{* h}$ for every $h \in H$,

(ii) $\sum_{h \in H} \tilde{x}_{t^{\prime} \mid t^{\prime}}^{h}=\sum_{h \in H} e_{t^{\prime} \mid t^{\prime}}^{h}$

(iii) $\tilde{x}_{\cdot \mid t^{\prime}}^{h} \succeq_{-x_{-\mid t^{\prime}}^{* h}} x_{\cdot \mid t^{\prime}}^{* h}$ for all $h \in H$, and

(iv) $\tilde{x}_{\cdot \mid t^{\prime}}^{h^{\prime}} \succ_{x_{-\mid t^{\prime}}^{* h^{\prime}}} x_{\cdot \mid t^{\prime}}^{* h^{\prime}}$ for some $h^{\prime} \in H$.

Since preferences are independent of consumption in the past, optimal consumption is also not dependent on consumption in the past. Similarly, optimal future consumption is independent of current and past consumption. Therefore, the only reason why household $h^{\prime}$ has not chosen $\tilde{x}_{\cdot \mid t^{\prime}}^{h^{\prime}}$ is that its period- $t^{\prime}$ component must be too expensive. Similarly, for every household $h$ the period- $t^{\prime}$ component of $\tilde{x}_{\cdot \mid t^{\prime}}^{h}$ must be at least as expensive as the period- $t^{\prime}$ component of $x_{\cdot \mid t^{\prime}}^{* h}$. This can be summarized as

$$
\begin{aligned}
& p_{t^{\prime} \mid t^{\prime}}^{*} \tilde{x}_{t^{\prime} \mid t^{\prime}}^{h^{\prime}}>p_{t^{\prime} \mid t^{\prime}}^{*} x_{t^{\prime} \mid t^{\prime}}^{* h^{\prime}}, \text { and } \\
& p_{t^{\prime} \mid t^{\prime}}^{*} \tilde{x}_{t^{\prime} \mid t^{\prime}}^{h} \geq p_{t^{\prime} \mid t^{\prime}}^{*} x_{t^{\prime} \mid t^{\prime}}^{* h} \text { for every household } h \in H .
\end{aligned}
$$


As in the proof of Theorem 5.6 this leads to a contradiction. It follows that the sophisticated equilibrium allocation $x^{*}$ must be CMP efficient.

Q.E.D.

\section{Theorem 6.3}

Assume that preferences are time-consistent and satisfy Assumption 6'. If a time-consistent allocation is Pareto efficient, then it is OP efficient.

Proof

Let $x^{*}$ be a time-consistent allocation that is Pareto efficient. Suppose that $x^{*}$ is not OP efficient. Then there must be an allocation $\tilde{x}$ and a period $t^{\prime}$ such that

(i) $\sum_{h \in H} \tilde{x}_{\cdot t}^{h}=\sum_{h \in H} e_{\cdot \mid t}^{h}$ for all $t \geq t^{\prime}$,

(ii) $\left(x_{-\mid t^{\prime}}^{* h}, \tilde{x}_{t^{\prime} \mid t^{\prime}}^{h}, \ldots, \tilde{x}_{t-1 \mid t-1}^{h}, \tilde{x}_{\cdot \mid t}^{h}\right) \succeq^{* h, t}\left(x_{-\mid t}^{* h}, x_{\cdot \mid t}^{* h}\right)=x_{\cdot \mid 1}^{* h}$ for all $h \in H$ and all $t \geq t^{\prime}$, and

(iii) $\left(x_{-\mid t^{\prime}}^{* h^{\prime}}, \tilde{x}_{t^{\prime} \mid t^{\prime}}^{h^{\prime}}, \ldots, \tilde{x}_{t^{\prime \prime}-1 \mid t^{\prime \prime}-1}^{h^{\prime}}, \tilde{x}_{\cdot \mid t^{\prime \prime}}^{h^{\prime}}\right) \succ^{* h^{\prime}, t^{\prime \prime}}\left(x_{-\mid t^{\prime \prime}}^{* h^{\prime}}, x_{\cdot \mid t^{\prime \prime}}^{* h^{\prime}}\right)=x_{\cdot \mid 1}^{* h^{\prime}}$ for some $h^{\prime} \in H$ and some $t^{\prime \prime} \geq t^{\prime}$

Then, by Assumption 6', we have

(ii) $\left(x_{-\mid t}^{* h}, \tilde{x}_{\cdot \mid t}^{h}\right) \succeq^{* h, t} x_{\cdot \mid 1}^{* h}$ for all $h \in H$ and all $t \geq t^{\prime}$, and

(iii) $\left(x_{-\mid t^{\prime \prime}}^{* h^{\prime}}, \tilde{x}_{\cdot \mid t^{\prime \prime}}^{h^{\prime}}\right) \succ^{* h^{\prime}, t^{\prime \prime}} x_{\cdot \mid 1}^{* h^{\prime}}$ for some $h^{\prime} \in H$ and some $t^{\prime \prime} \geq t^{\prime}$.

By time-consistency of preferences it then follows that

(ii) $\left(x_{-\mid t^{\prime \prime}}^{* h}, \tilde{x}_{\cdot \mid t^{\prime \prime}}^{h}\right) \succeq^{* h, 1} x_{\cdot \mid 1}^{* h}$ for all $h \in H$, and

(iii) $\left(x_{-\mid t^{\prime \prime}}^{* h^{\prime}}, \tilde{x}_{\cdot \mid t^{\prime \prime}}^{h^{\prime}}\right) \succ^{* h^{\prime}, 1} x_{\cdot \mid 1}^{* h^{\prime}}$.

Since $\sum_{h \in H}\left(x_{-\mid t^{\prime \prime}}^{* h}, \tilde{x}_{\cdot \mid t^{\prime \prime}}^{h}\right)=e_{\cdot \mid 1}^{h}$ by definition of $x^{*}$, this would imply that $x^{*}$ is not Pareto efficient, which is a contradiction. Thus, $x^{*}$ must be OP efficient.

Q.E.D.

\section{Theorem 6.6}

Assume that preferences are time-consistent and satisfy Assumption 6'. If a time-consistent allocation is Pareto efficient then it is TCOP efficient.

\section{Proof}

Let the time-consistent allocation $x^{*}$ be Pareto efficient. Then it follows by Theorem 6.3 that $x^{*}$ is OP efficient. By the definitions it then follows immediately that $x^{*}$ is TCOP efficient.

Q.E.D. 


\section{Theorem 6.7}

In an economy $\mathcal{E}$ that satisfies Assumptions 2, 3, 4, and 6', a sophisticated equilibrium allocation is TCOP efficient.

Proof

Let $\left(p^{*}, x^{*}\right)$ be a sophisticated equilibrium. Suppose that $x^{*}$ is not TCOP efficient. Then, there must be a time-consistent reallocation $\tilde{x}$ and a period $t^{\prime}$ that satisfy

(i) $\sum_{h \in H} \tilde{x}_{\cdot \mid 1}^{h}=\sum_{h \in H} e_{\cdot \mid 1}^{h}$,

(ii) $\left(x_{-\mid t^{\prime}}^{* h}, \tilde{x}_{\cdot \mid t^{\prime}}^{h}\right) \succeq^{* h, t} x_{\cdot \mid 1}^{* h}$ for all $h \in H$ and all $t \geq t^{\prime}$, and

(iii) $\left(x_{-\mid t^{\prime}}^{* h^{\prime}}, \tilde{x}_{\cdot \mid t^{\prime}}^{h^{\prime}}\right) \succ^{* h^{\prime}, t^{\prime \prime}} x_{\mid \cdot 1}^{* h^{\prime}}$ for some $h^{\prime} \in H$ and some $t^{\prime \prime} \geq t^{\prime}$.

If $t^{\prime \prime}=T$ then, since preferences are independent of past consumption, we must have

$$
\begin{aligned}
& p_{T \mid 1}^{*} \tilde{x}_{T \mid t^{\prime}}^{h^{\prime}}>p_{T \mid 1}^{*} x_{T \mid 1}^{* h^{\prime}}, \text { and } \\
& p_{T \mid 1}^{*} \tilde{x}_{T \mid t^{\prime}}^{h} \geq p_{T \mid 1}^{*} x_{T \mid 1}^{* h} \text { for every household } h \in H,
\end{aligned}
$$

which yields a contradiction as before. Now assume that for every household $h$ and every $\tilde{t}>t$ we have

$$
\begin{array}{rll}
p_{\hat{t} \mid 1}^{*} \tilde{x}_{\hat{t} \mid t^{\prime}}^{h} & \leq & p_{\hat{t} \mid 1}^{*} x_{\hat{t} \mid 1}^{* h} \\
\left(x_{-\mid t^{\prime}}^{* h}, \tilde{x}_{\mid t^{\prime}}^{h}\right) & \succeq^{* h, \tilde{t}} & x_{\cdot \mid 1}^{* h} .
\end{array}
$$

Since preferences are independent of past consumption it follows that $\tilde{x}_{|| \tilde{t}}^{h}$ must be an optimal consumption in period $\tilde{t}$ given prices $p_{\tilde{t} \mid 1}^{*}$. Now assume that $t^{\prime \prime}=t$. Then we must have

$$
\begin{aligned}
& p_{t \mid 1}^{*} \tilde{x}_{t \mid t^{\prime}}^{h^{\prime}}>p_{t \mid 1}^{*} x_{t \mid 1}^{* h^{\prime}}, \text { and } \\
& p_{t \mid 1}^{*} \tilde{x}_{t \mid t^{\prime}}^{h} \geq p_{t \mid 1}^{*} x_{t \mid 1}^{* h} \text { for every household } h \in H,
\end{aligned}
$$

which again leads to a contradiction. Continuing like this we end up with this contradiction for $t=t^{\prime}$, so that case (iii) can never hold.

It follows that the sophisticated equilibrium allocation $x^{*}$ must be TCOP efficient.

Q.E.D.

\section{Theorem 6.10}

If a time-consistent allocation is TCOP efficient, then it is CP efficient.

Proof

Let the time-consistent allocation $x^{*}$ be TCOP efficient. Suppose that $x^{*}$ is not CP efficient. Then there is an allocation $\tilde{x}$ and a period $t^{\prime}$ such that 
(i) $\tilde{x}_{t^{\prime}+1, T \mid t^{\prime}}^{h}=x_{t^{\prime}+1, T \mid t^{\prime}}^{* h}=x_{t^{\prime}+1, T \mid 1}^{* h}$ for every $h \in H$,

(ii) $\sum_{h \in H} \tilde{x}_{t^{\prime} \mid t^{\prime}}^{h}=\sum_{h \in H} e_{t^{\prime} \mid t^{\prime}}^{h}$

(iii) $\left(x_{-\mid t^{\prime}}^{* h}, \tilde{x}_{\cdot \mid t^{\prime}}^{h}\right) \succeq^{* h, t}\left(x_{-\mid t}^{* h}, x_{\cdot \mid t}^{* h}\right)=x_{\cdot \mid 1}^{* h}$ for all $h \in H$ and all $t \geq t^{\prime}$, and

(iv) $\left(x_{-\mid t^{\prime}}^{* h^{\prime}}, \tilde{x}_{\cdot \mid t^{\prime}}^{h^{\prime}}\right) \succ^{* h^{\prime}, t^{\prime \prime}}\left(x_{-\mid t^{\prime \prime}}^{* h^{\prime}}, x_{\cdot \mid t^{\prime \prime}}^{* h^{\prime}}\right)=x_{\cdot \mid 1}^{* h^{\prime}}$ for some $h^{\prime} \in H$ and some $t^{\prime \prime} \geq t^{\prime}$,

which contradicts the fact that $x^{*}$ is TCOP efficient.

Q.E.D.

\section{Theorem 6.11}

In an economy $\mathcal{E}$ that satisfies Assumptions 2, 3, 4, and 6', naïve and sophisticated equilibrium allocations are CP efficient.

\section{Proof}

For sophisticated equilibria the result follows directly from Theorems 6.10 and 6.7, since sophisticated equilibrium allocations are time-consistent. Now let $\left(p^{*}, x^{*}\right)$ be a naïve equilibrium. Suppose that $x^{*}$ is not CP efficient. Then there must be a reallocation $\tilde{x}$ and a period $t^{\prime}$ that satisfy

(i) $\tilde{x}_{t^{\prime}+1, T \mid t^{\prime}}^{h}=x_{t^{\prime}+1, T \mid t^{\prime}}^{* h}$ for every $h \in H$,

(ii) $\sum_{h \in H} \tilde{x}_{t^{\prime} \mid t^{\prime}}^{h}=\sum_{h \in H} e_{t^{\prime} \mid t^{\prime}}^{h}$

(iii) $\left(x_{-\mid t^{\prime}}^{* h}, \tilde{x}_{\cdot \mid t^{\prime}}^{h}\right) \succeq^{* h, t}\left(x_{-\mid t}^{* h}, x_{\cdot \mid t}^{* h}\right)$ for all $h \in H$ and all $t \geq t^{\prime}$, and

(iv) $\left(x_{-\mid t^{\prime}}^{* h^{\prime}}, \tilde{x}_{\cdot \mid t^{\prime}}^{h^{\prime}}\right) \succ^{* h^{\prime}, t^{\prime \prime}}\left(x_{-\mid t^{\prime \prime}}^{* h^{\prime}}, x_{\cdot \mid t^{\prime \prime}}^{* h^{\prime}}\right)$ for some $h^{\prime} \in H$ and some $t^{\prime \prime} \geq t^{\prime}$.

Since $\tilde{x}_{t^{\prime \prime}, T \mid t^{\prime}}^{h^{\prime}}$ was not demanded in equilibrium by household $h^{\prime}$ in period $t^{\prime \prime}$, it must hold that for some $\tilde{t} \geq t^{\prime \prime}$

$$
\begin{aligned}
& p_{\tilde{t} \mid t^{\prime \prime}}^{*} \tilde{x}_{\tilde{t} \mid t^{\prime}}^{h^{\prime}}>p_{\tilde{t} \mid t^{\prime \prime}}^{*} x_{\hat{t} \mid t^{\prime}}^{* h^{\prime}}, \text { and } \\
& p_{\tilde{t} \mid t^{\prime \prime}}^{*} \tilde{x}_{\tilde{t} \mid t^{\prime}}^{h} \geq p_{\tilde{t} \mid t^{\prime \prime}}^{*} x_{\tilde{t} \mid t^{\prime}}^{* h} \text { for every household } h \in H,
\end{aligned}
$$

which leads to a contradiction as before. Thus, $x^{*}$ must be CP efficient.

Q.E.D.

\section{References}

Ainslie, G., and N. Haslam (1992), "Hyperbolic Discounting," in G. Loewenstein and J. Elster (eds.), Choice over Time, Russell Sage Foundation, New York, pp. 57-92.

Angeletos, G.M., D. Laibson, A. Repetto, J. Tobacman, and S. Weinberg (2001), "The Hyperbolic Consumption Model: Calibration, Simulation, and Empirical Evaluation," Journal 
of Economic Perspectives, 15, 47-68.

Arrow, K.J. (1953), "Le Rôle des Valeurs Boursières pour la Répartition la Meilleure des Risques," in Econométrie, Colloques Internationaux du Centre National de la Recherce Scientifique, 40, 41-47; English version: "The Role of Securities in the Optimal Allocation of Risk-Bearing," Review of Economic Studies, 31, 91-96.

Benhabib, J., and A. Bisin (2002), "The Psychology of Self-control and Consumptionsaving Decisions: Cognitive Perspectives," Working Paper, 1-33.

Citanna, A., A. Kajii, and A. Villanacci (1998), "Constrained Suboptimality in Incomplete Markets: a General Approach and Two Applications," Economic Theory, 11, 495-521.

Debreu, G. (1959), Theory of Value, John Wiley, New York.

Dutta, J., and S. Morris (1997), "The Revelation of Information and Self-fulfilling Beliefs," Journal of Economic Theory, 73, 231-244.

Frederick, S., G. Loewenstein, and T. O’Donoghue (2002), "Time Discounting and Time Preference: a Critical Review," Journal of Economic Literature, 40, 351-401.

Geanakoplos, J.D., and H.M. Polemarchakis (1986), "Existence, Regularity, and Constrained Suboptimality of Competitive Allocations when the Asset Market is Incomplete," in W.P. Heller, R.M. Starr, and D.A. Starrett (eds.), Uncertainty, Information and Communication: Essays in Honor of K.J. Arrow, Vol. III, Cambridge University Press, Cambridge, pp. $65-96$.

Herings, P.J.J., and H. Polemarchakis (2004), "Pareto Improving Price Regulation when the Asset Market is Incomplete," forthcoming in Economic Theory.

Hoch, S.J., and G.F. Loewenstein (1991), "Time-inconsistent Preferences and Consumer Self-control," Journal of Consumer Research, 17, 492-507.

Krussel, P., B. Kuruşçu, and A.A. Smith (2002), "Equilibrium Welfare and Government Policy with Quasi-geometric Discounting," Journal of Economic Theory, 105, 42-72.

Laibson, D. (1997), "Golden Eggs and Hyperbolic Discounting," Quarterly Journal of 
Economics, 112, 443-477.

Laibson, D. (1998), "Life-cycle Consumption and Hyperbolic Discount Functions," European Economic Review, 42, 861-871,

Loewenstein, G., and D. Prelec (1992), "Anomalies in Intertemporal Choice: Evidence and an Interpretation," Quarterly Journal of Economics, 107, 573-597.

Luttmer, E.G.J., and T. Mariotti (2002), "Efficiency and Equilibrium when Preferences are Time-inconsistent," Working Paper, 1-29.

Luttmer, E.G.J., and T. Mariotti (2003), "Subjective Discounting in an Exchange Economy," Journal of Political Economy, 111, 1-30.

O’Donoghue, T., and M. Rabin (1999), "Doing it now or later," American Economic Review, 89, 103-124.

Pollak, R.A. (1968), “Consistent Planning," Review of Economic Studies, 35, 201-208.

Rachlin, H., and A. Raineri (1992), "Irrationality, Impulsiveness, and Selfishness as Discount Reversal Effects," in G. Loewenstein and J. Elster (eds.), Choice over Time, Russell Sage Foundation, New York, pp. 93-118.

Radner, R. (1972), "Existence of Equilibrium of Plans, Prices, and Price Expectations in a Sequence of Markets," Econometrica, 40, 289-303.

Thaler, R.H. (1991), "Some Empirical Evidence on Dynamic Inconsistency," in R.H. Thaler (ed.), Quasi Rational Economics, Russell Sage Foundation, New York, pp. 127-133. 